\title{
तิ \\ El viviente y su medio: antes y después de Darwin
}

\author{
Gustavo Caponi
}

\begin{abstract}
茴
RESUMEN

Las reiteradas referencias a un presunto adaptacionismo predarwiniano que encontramos en la literatura actual sobre biología evolucionaria pueden propiciar una imagen distorsionada de los temas y problemas que realmente ocupaban a los naturalistas predarwinianos y de la importancia que éstos efectivamente le concedían al estudio de las complejas relaciones que las particularidades morfológicas de los seres vivos guardan con las exigencias ambientales. En este trabajo, intentaré mostrar que ese último tópico no ocupaba un lugar de destaque en la historia natural que antecede inmediatamente a la revolución darwiniana; y sugeriré que esa indiferencia estaba asociada a la persistencia de una economía natural en donde cada ser vivo tenía una función a cumplir y no un lugar a conquistar y a defender. Por último, mostraré cómo el cambio de actitud hacia ese tópico estimulado por el darwinismo impactó en el trabajo de los naturalistas de campo.
\end{abstract}

Palabras-clave • Buffon. Cuvier. Darwin. Saint-Hilaire. Humboldt. Lamarck. Paley.

\section{Presentación}

Defensores de un adaptacionismo a ultranza como A. J. Cain (1989 [1964], p. 3-6), críticos de esta posición como S. J. Gould (2002, p. 330) e incluso historiadores de la biología evolucionaria, como R. Amundson (1998, p. 154; 2001, p. 3o7) o M. Ruse (1983, p. 189), coinciden en sostener que la visión utilitaria de las estructuras orgánicas preconizada por el darwinismo tiene antecedentes que remiten a la historia natural anterior a 1859; y entre esos antecedentes suelen citar, no sólo a la teología natural de Paley, sino también a los trabajos y a las concepciones de Cuvier y, sobre todo, Lamarck. Creo, sin embargo, que esas referencias a un presunto adaptacionismo predarwiniano, por inocentes o poco problemáticas que parezcan, pueden propiciar una imagen distorsionada de los temas y problemas que realmente ocupaban a los naturalistas predarwinianos y de la importancia que éstos efectivamente le concedían al estudio y al análisis de las complejas relaciones que las particularidades morfológicas de los seres vivos pudiesen guardar con las exigencias ambientales y, sobre todo, con aquellas exigencias, desafíos y oportunidades planteadas por otros seres vivos. 
Por eso, en las páginas que siguen, intentaré mostrar que ese último tópico no ocupaba un lugar de destaque en la historia natural que antecede inmediatamente a la revolución darwiniana; y para ello me referiré en particular, pero no exclusivamente y de un modo inevitablemente sucinto, a las obras de Lamarck, Cuvier, Isidore Geoffroy de Saint-Hilaire y Humboldt. Mi idea es que, a este respecto, existen ciertas diferencias muy significativas entre los intereses y preocupaciones de estos autores y aquellas que caracterizan a la historia natural darwiniana; diferencias que, según me permitiré sugerir, obedecen al hecho de que, contrariamente a lo que ocurre con Darwin, Wallace y sus seguidores, aquellos otros autores aun eran tributarios de una idea de economía natural en donde cada ser tenía una función a cumplir y no un lugar a conquistar y a defender. Ya por último, aludiré al impacto que ese cambio de intereses propiciado por el darwinismo tuvo en el trabajo de los naturalistas de campo.

\section{De Linneo a Buffon}

Como es sabido, a partir de obras como The wisdom of God manifested in the works of creation publicada por John Ray ya en 1692, y la Physico-theology publicada por William Derham en 1713, el tópico de la correlación existente entre estructuras orgánicas y exigencias ambientales cobró algún relieve en la historia natural inglesa del siglo xviıI (cf. Drouin, 1993, p. 39; Bowler, 1998, p. 109 ss.). Pero, como esos títulos lo indican, el tópico era allí tratado como una cuestión teológica planteada casi en los limites de una historia natural que, en sentido estricto, era mayormente entendida como una actividad puramente taxonómica (Rehbock, 1983, p. 5). Para esos autores, anclados todos ellos en una tradición del pensamiento inglés que remonta a Newton y a Boyle, tanto la mutua coadaptación de las estructuras orgánicas en el seno del viviente individual, como su no menos notable ajuste a las condiciones de vida que le eran propias, podía ser considerada como una evidencia empírica de la sabiduría y de la bondad divinas (cf. Limoges, 1976, p. 50-1; Cronin, 1991, p. 11-3; Burkhardt, 1995, p. 72; Gould, 2002, p. 65; Ruse, 2005); y es bajo ese mismo leitmotiv que Linneo ${ }^{1}$ retoma el tema enfatizando sobre todo el modo en que las estructuras biológicas estaban dispuestas de forma tal que permitiesen que los seres vivos ocupen su lugar y cumplan su papel en la economía

1 El pensamiento de Linneo a este respecto está claramente expuesto en las tesis pro exercitio de tres de sus alumnos: Oeconomia naturae defendida por I. J. Biberg en 1749, Gui bono defendida por C. Gedner en $175^{2}$ y Politia naturae defendida por H. C. D. Wilcke en 1760. Linneo, de hecho, se consideraba a sí mismo como autor de esos trabajos y ésta era una actitud acorde con una tradición académica danesa conforme la cual la autoría de este tipo de tesis debía siempre ser atribuida a los propios tutores u orientadores (cf. Limoges, 1972, p. 8-9). 
natural (cf. Limoges, 1972, p. 10; Acot, 1988, p. 16; Drouin, 1993, p. 39 ss.; Bowler, 1998, p. 123 ss.).

Siendo que lo que allí se entendía por economía natural no era otra cosa que "la muy sabia disposición de los seres naturales, instituida por el soberano creador, según la cual tales seres tienden a fines comunes y poseen funciones reciprocas" (Biberg, $192^{2}$ [1749], p. 57-8). Así, conforme Linneo se lo hace decir a su alumno Christophorus Gedner:

En cada planta, en cada insecto, observaremos alguna habilidad particular que no encontramos en los otros cuerpos. Y, después de haberlos comparado entre ellos, constatamos que eso no fue hecho al azar, sino con un fin preciso y determinado, por una causa determinada, que sirve, sea a la propagación de la planta o del animal, sea a su conservación, sea en función de aquellos otros seres con los que se vincula. Constatamos cómo las plantas se conservan contra los rigores de los elementos y contra los ataques de los animales; cómo cada animal goza de sus medios de defensa, gracias a los cuales se puede proteger de los ataques de los otros; de tal manera que nada de aquello que ha sido creado pueda ser destruido (Linné, 1972 [1752], p. 164,-5).

Y es esa misma perspectiva linneana que sirve de base para la Natural theology que Paley publica en 1805. En esta obra, leída y releída obsesivamente por Darwin (cf. 1892, p. 19) durante sus años de estudiante de teología en Cambridge (cf. Ruse, 2005, p. 35; Desmond \& Moore, 2000, p. 109), nos encontramos con ciertos análisis de algunas singularidades morfológicas de distintos seres vivos que, como muchas veces se lo ha observado, parecen prefigurar la perspectiva utilitaria propiciada por la teoría de la selección natural (cf. Ruse, 1983, p. 232; Gould, 1994, p. 138). En ella, por ejemplo, la lengua del pájaro carpintero, a la cual también se alude en El origen de las especies como ejemplo privilegiado de artilugio (contrivance) adaptativo, es citada y analizada en función de su adecuación como recurso para la captura de insectos que habitan en troncos. La misma, nos dice Paley, "es un instrumento particular para un uso particular" (1809, p. 250) cuya existencia sólo puede explicarse por la mediación de un designio o intención. ${ }^{2}$

2 La palabra que Paley usa es, claro, design: una expresión cuya traducción a las lenguas latinas no deja de ser problemática. Es que, en el castellano, al igual que en el portugués y en el francés, la misma puede ser traducida de dos formas: por designio o por diseño en el caso del castellano, por desígnio o por desenho en el caso del portugués y por dessein o dessin en el caso del francés. Siendo que en los tres casos la segunda alternativa sirve para designar tanto el proceso por el cual se produce el modelo de alguna cosa como el resultado mismo de ese proceso; e igualmente en los tres casos la primera alternativa equivale a intención o a plan. En el caso del pasaje de Paley que acabo de citar, 
Es necesario remarcar, sin embargo, que, en su mayor parte, los ejemplos de diseño orgánico a los que Paley apela en sus argumentos aluden mucho menos a roles biológicos, como el de la lengua del pájaro carpintero, que a la mutua correlación e integración de las partes en el interior de cada ser vivo y a sus funciones en la preservación de lo que él llama de economía animal (Paley, 1809, p. 268). A Paley, la correlación funcional de las partes parece interesarle más que la eventual utilidad ecológica de las mismas; y su Teología natural es definitivamente mucho más rica en descripciones anatómicas y fisiológicas que en análisis que puedan recordarnos a las narraciones adaptacionistas darwinianas. La secreción de jugos gástricos útiles para la digestión (Paley, 1809, p. 90-1), las complejas relaciones de mutua interdependencia que guardan entre sí los huesos y las articulaciones del esqueleto humano (Paley, 18o9, Cap. 8), la disposición de los músculos con su maravillosa aptitud para producir el movimiento (Paley, 1809, Cap. 9) y la compleja red de los vasos sanguíneos (Paley, 1809, Cap. 10) constituyen, sin ninguna duda, los puntos más fuertes de su argumentación.

Pero eso es comprensible: como observó William James, “para el gorgojo bajo la corteza, la admirable adecuación del organismo del pájaro carpintero para extraerlo ciertamente implica un diseñador diabólico" (1974 [1907], p. 80); y aunque Paley (1809, p. 468 ss.) haya intentando esbozar una justificación teológica para la existencia de antagonismos entre los seres vivos y para la posesión, por parte de éstos, de estructuras diseñadas para producir daños en otras especies, lo cierto es que ese tipo de fenómenos no dejaban de constituir una dificultad dentro de su línea general de argumentación (cf. Horta, 2005, p. 128-31). Las contrivances, o artilugios, de significación puramente fisiológica y la exquisita complejidad de la economía animal constituían para él tópicos mucho más fácilmente transitables y definitivamente más adecuados para demostrar, no solo la existencia y la inteligencia del creador, sino también su suprema benevolencia para con sus humildes criaturas; y en todo caso, si se quería ir un poco más allá de esos análisis relativos a la mutua conveniencia de las partes en el seno del

creo que es claro que la traducción adecuada es designio y no diseño; pero en muchas otras partes del texto de Paley la opción parece menos clara: ¿cómo deberíamos decir, argumento del designio o argumento del diseño? Design es un término definitivamente equívoco y esa equivocidad ha sido secularmente explotada por los defensores del argument from design porque refuerza la proximidad entre las ideas de propósito y diseño. Felizmente esa superposición no es forzosa en nuestras lenguas: distinguiendo entre diseño y designio en castellano, al igual que en portugués y en francés, se puede pensar, o por lo menos hablar, de la producción de un diseño sin un designio que la oriente. Para nosotros, en suma, la idea de que la selección natural diseña los organismos sin designio alguno no tiene la apariencia inmediata de un contrasentido. Esto tal vez ayude a explicar la mayor persistencia, y el fastidioso retorno, de ese argumento teológico en algunos países de lengua inglesa. Pienso, sobre todo, en los cultores actuales de la idea de inteligent design. De todos modos, Darwin nos sirve como una prueba arto elocuente de que esta dificultad léxica no constituye un obstáculo epistemológico demasiado serio. 
propio organismo, se podía dirigir la mirada a la relación que los cuerpos animados guardan con su entorno físico inmediato.

Así, al introducir este último tópico en el inicio de su décimo séptimo capítulo titulado "La relación de los cuerpos animados con la naturaleza inanimada", Paley (1809, p. 291 ss.) nos dice que hasta ahí se han considerado las relaciones que guardan "las partes de un animal con otras partes del mismo animal, o con aquellas de otro individuo de la misma especie"; pero, según él mismo agrega, "los cuerpos de los animales" también guardan, "en su constitución y propiedades, una estrecha e importante relación con naturalezas externas a él". Los cuerpos vivos, en efecto, "guardan una estrecha relación con los elementos por los cuales están rodeados" (Paley, 1809, p. 291); y en esa conveniencia que existe entre el ala del ave y el medio aéreo y entre la aleta del pez y el medio acuático, Paley encontraba una evidencia de la existencia y la generosidad divinas mucho más directa y contundente que esas conflictivas e insidiosas relaciones que los seres vivos guardan entre sí y que luego Darwin pondría en el centro de las atenciones de la historia natural.

Pero, independientemente de estos matices que acabo de apuntar, y más allá del reconocimiento y del espacio que esa teología natural todavía pudiese tener en la Inglaterra de inicios del siglo xix, ${ }^{3}$ lo cierto es que los naturalistas más influyentes y representativos de ese periodo no muestran mayor interés en analizar o en considerar las correspondencias que podían existir entre peculiaridades morfológicas de las diferentes especies y las exigencias ambientales a que estas estaban sometidas; y, por lo menos en lo que respecta a este asunto en particular, ese desinterés parece alejar a la historia natural del espíritu de Linneo, aproximándola a los puntos de vista de su rival Buffon.

Este último, pese a su conocida insistencia en asuntos vinculados con la distribución y la variación geográfica de los seres vivos, nunca mostró mayor interés en pensar a las estructuras morfológicas como siendo recursos para resolver problemas particulares de supervivencia. ${ }^{4}$ Sus análisis subrayaban, es cierto, la supuesta influencia que

3 No es Inglaterra, sin embargo, el único lugar en donde ese tipo de apreciación de las estructuras orgánicas pervivió más allá de Linneo. En Alemania, Schopenhauer (1985 [1819], p. 148; 1947 [1857], p. 75) supo valerse de cierto adaptacionismo avant la lettre para justificar su metafísica de la voluntad; e incluso lo hizo reivindicando también la idea clásica de economía natural.

4 Una actitud en cierto modo crítica a la de Buffon puede ser encontrada en algunos naturalistas de fines del xviıI e inicios del xıx como François Levaillant, François-Marie Daudin, Julien Virey y Charles Sonini (cf. Corsi, 2001, p. 120-5; Burkhardt, 1995, p. xxv-xxvi). Es digno de resaltar, sin embargo, que conforme lo que Corsi y Burkhardt nos dejan ver en sus trabajos sobre Lamarck, estos autores parecían razonar al modo cuvieriano y no al modo darwiniano: para ellos, la estructura, la organización, determinaba o condicionaba el modo de vida y no a la inversa (cf. Corsi, 2001, p. 125-9; Burkhardt, 1995, p. xxvii-xxx). 
el clima y la alimentación tendrían sobre los perfiles y sobre la distribución de los organismos (cf. Buffon, 174,9, p. 528-9; 1761, p. 107, 127; 1766, p. 320-1; Flourens, 1850, p. 154; Rostand, 1958, p. 602; Roger, 1983, p. 156; Papavero et al., 1997, p. 165; Bowler, 1998, p. 133); pero, desde su perspectiva, esas influencias, lejos de optimizar las formas o de modelarlas en beneficio de los animales, sólo producían una degeneración del tipo originario (cf. Roger, 1983, p. 169).

"Lo que está totalmente ausente en el pensamiento de Buffon", lo dice claramente Jacques Roger (1983, p. 169), “es la noción de adaptación”. Contemporáneo de Linneo, "Buffon tuvo frente a sí a naturalistas creacionistas que gustaban de subrayar la admirable adaptación de los seres vivos a sus condiciones de vida". Pero, en lugar de buscar como Darwin un mecanismo capaz de explicar naturalmente esta adaptación, "Buffon prefiere negarla" (cf. Shanahan, 2004, p. 96); y esa actitud parece haber marcado e influenciado a la totalidad, o a la mayor parte, de esa generación de naturalistas que lo sucede en el Jardín du Roi devenido Museo Nacional de Historia Natural después de la revolución. Tal es el caso, inclusive, de su protegido Lamarck.

\section{LAMARCK: UN BUFFONIANO RADICAL 5}

Los escritos de éste mencionan, es cierto, múltiples peculiaridades morfológicas que hoy consideraríamos ejemplos de adaptaciones; pero si los leemos atentamente veremos que esos ejemplos no son allí interpretados de ese modo. La singularidad morfológica puede ser hoy un indicio poderoso de adaptación; pero no lo era para Lamarck. Para él, claro, esa singularidad merecía y podía ser explicada: merecía serlo en tanto la misma constituyese una anomalía en relación a la serie o escala natural de las formas; y podía serlo apelando a los fenómenos fisiológicos que la acción de las circunstancias podían desencadenar en los organismos individuales. Pero esa explicación no presuponía ni apelaba a la supuesta utilidad que el rasgo en cuestión pudiese eventualmente comportar para sus portadores. La verdadera batalla de Lamarck fue siempre la defensa, tal vez tardía, de la serie o escala de los seres, tanto en el plano de la botánica como en el de la zoología; y es en el contexto de esa concepción general en donde debemos situar sus ideas sobre la influencia de las circunstancias en las conformaciones de los organismos (cf. Daudin, 1927, p. 111-8; Mayr, 1976, p. 233-4; Jordanova, 1990, p. 108-9; Burkhardt, 1995, p. 140-1).

5 En Caponi (no prelo) desarrollo una versión más completa de la crítica a la lectura adaptacionista de Lamarck que aquí presento. 
Lo que habitual y descuidadamente se considera como la teoría lamarckiana de la adaptación no era más, en este sentido, que un recurso para explicar el hecho de que las formas vivas particulares presenten peculiaridades organizacionales que no nos permiten alinearlas sucesivamente como eslabones contiguos de una serie de complejidad o perfección creciente (cf. Jacob, 1973, p. 167; Balan, 1979, p. 184; Guillo, 2003, p. 128; Nordenkiold, 1949, p. 368; Gillispie, 1959, p. 270; Barthélemy-Madaule, 1979, p. 71; Pichot, 1993, p. 666; Ruse, 1998, p. 72). Pero, lo que más me interesa subrayar aquí es que esa teoría no era tampoco, hablando rigurosamente, una teoría de la adaptación; y no lo era porque nunca, en ninguna parte, Lamarck presenta o piensa a las modificaciones producidas por las circunstancias, o por las reacciones de los organismos frente a esas circunstancias, como siendo útiles o ventajosas para sus portadores o como surgiendo para dar respuesta a algún problema particular planteado por el ambiente.

Decir que "Lamarck pretende que la respuesta al medio es siempre favorable" (Tetry, 1981, p. 146) o que desde su perspectiva "todas las variaciones que acontecen son útiles" (Jacob, 1973, p. 167) es un error muy común y persistente; pero no deja de ser un error. Y lo que está en la base de ese equívoco es la propensión a leer Lamarck como Darwin lo hizo (cf. Limoges, 1976, p. 49); es decir: como si fuese "un autor que trata el problema de la adaptación para darle una solución insatisfactoria" (Limoges, 1976, p. 48). Darwin nos lleva, en efecto, a leer Lamarck como si este fuese su precursor; y esto vale incluso para aquellos autores usualmente denominados neolamarckianos. Las así llamadas teorías neolamarckianas siempre fueron deudoras del darwinismo: suponían planteada la problemática de la adaptación y se remitían a los escritos de Lamarck como fuente de soluciones alternativas para la misma. Pero sólo es necesario fracasar en la tentativa de encontrar en Lamarck cualquier referencia clara y inequívoca a la utilidad o la conveniencia de las modificaciones producidas por las circunstancias para percibir que lo que allí está en juego es un problema distinto del darwiniano.

Para Lamarck, en efecto, las modificaciones que los organismos sufrían en virtud de sus condiciones de vida no tenían porque redundar en alguna ventaja para sus portadores; y es por eso que la posible utilidad de las mismas no era nunca considerada en sus análisis y explicaciones. Lejos de ser pensadas como recursos para enfrentar las circunstancias, esas modificaciones eran, en todo caso, marcas o deformaciones producidas por las condiciones en las que se desarrollaban las diferentes formas de vida. Así, como los ojos de un topo no se atrofian para dejar de ver; sino por dejar de hacerlo, el pescuezo de la jirafa no se estiraba porque eso permitiese alcanzar las ramas más altas de los árboles sino por el movimiento reiterado y continuo que ese animal realiza en su rutina de alimentación: el movimiento, o su ausencia, simplemente causa una modificación pero nada indica, a priori, que esa modificación tenga que ser necesariamente útil o ventajosa (cf. Lamarck, 1994 [1809], p. 232-3); y esto lo podemos constatar con 
mayor claridad aún en la explicación que Lamarck da del tamaño y la forma que llegan a tener los grandes cuadrúpedos herbívoros.

Estos animales, nos dice, además de poseer el "hábito de consumir, todos los días, grandes volúmenes de materia alimentar que distienden los órganos que los reciben"; poseen también el habito "de no hacer más que movimientos mediocres" y de eso "ha resultado que los cuerpos de estos animales se hayan engrosado considerablemente, hayan devenido pesados y macizos, y hayan adquirido un volumen muy grande como se lo ve en elefantes, rinocerontes, vacas, búfalos y caballos" (Lamarck, 1994 [1809], p. 229). En cambio, observa Lamarck, en las tierras donde la presencia de predadores obliga reiteradamente a correr, esos efectos no se han notado: el ejercicio les dio a gacelas y antílopes un cuerpo más esbelto. Pero esta esbeltez y ligereza no es una adaptación para la carrera, es un resultado o un efecto de la carrera.

Y algo semejante a lo que hemos dicho sobre la evolución de los herbívoros podríamos decir sobre la evolución del perezoso: Lamarck (1994 [1809], p. 234) la presenta, no como una progresiva adaptación a un modo de vida sino como un simple resultado de ese modo de vida. Lamarck no piensa darwinianamente: no busca una utilidad particular para las características del perezoso. Éstas no son vistas como configurando una estrategia de supervivencia sino como la simple consecuencia de las condiciones de vida a la que este animal se vio confinado; y lo que vale para el perezoso valdría también para cualquier tipo de animal cuyas condiciones de vida cambien y, de tener alimento en abundancia como un caballo europeo mantenido en un establo, pase a tener que depender de los escasos, magros y secos arbustos de la Patagonia: ese cambio generaría una raza de caballos menores. Pero esto sería un efecto directo y trasmisible a la descendencia de la falta de nutrientes; y no una adaptación darwiniana a esas condiciones. Sólo después de Darwin nuestro caballo criollo podrá ser visto como algo distinto de un caballo europeo degenerado por las difíciles circunstancias que le habrían tocado en suerte.

A este respecto, Lamarck está definitivamente más cerca de la temática buffoniana de la degeneración que de la temática darwiniana de la adaptación: y hasta puede decirse, que su teoría sobre la influencia de las circunstancias en los perfiles orgánicos no es otra cosa que una generalización y una radicalización de ese tímido, e inmediatamente desechado, atisbo de transformismo que Buffon (1868 [17533], p. 35-9) insinuó al sugerir la plausibilidad de considerar al asno como un simple caballo degenerado por los efectos del clima y de la alimentación acumulados a lo largo de generaciones. Para Lamarck, como para Buffon, las circunstancias deforman, degeneran o desvían, en mayor o menor grado, el normal desarrollo de las formas, pero no por eso las optimizan o las adecuan al cumplimiento de una función; y la diferencia es realmente importante: en otros contextos, el hecho de no verla podría llevarnos a confundir el retardo en el crecimiento de un niño desnutrido con un recurso o estrategia para encarar la escasez de alimentos. 
Pero, el mejor ejemplo para ver cómo la referencia a cualquier ventaja eventual de las modificaciones orgánicas producidas por las circunstancias esta ausente en el razonamiento de Lamarck, lo encontramos en su explicación de la formación de los cuernos de los rumiantes. Estos animales, nos dice Lamarck (1994 [1809], p. 230), "no pudiendo emplear sus pies más que para sostenerlos, y teniendo poca fuerza en sus mandíbulas, las cuales se ejercitan exclusivamente en cortar y masticar la hierba, sólo pueden batirse a golpes de cabeza, dirigiendo uno contra otro el vértice de esa parte"; y como sus accesos de cólera, sobre todo entre los machos, son frecuentes, "su sentimiento interior, por la mediación de esos esfuerzos, dirige más fuertemente los fluidos hacia esa parte de la cabeza" formándose allí "una secreción, de materia cornea en algunos casos, y de materia ósea mezclada de materia cornea en otros, que da lugar a protuberancias sólidas: de ahí el origen de los cuernos y las astas con los que la mayor parte de estos animales tienen la cabeza armada" (Lamarck, 1994 [1809], p. 231).

Lamarck, hay que reconocerlo, parece estar yendo demasiado lejos y forzando hasta lo insostenible las ideas usuales respecto a cómo los comportamientos repetidos pueden modificar los perfiles de un organismo. Pero, por eso mismo, este ejemplo sirve para mostrarnos cómo, sin ceder en ningún momento a la tentación de pensar que esas protuberancias estén ahí porqué sean útiles para algo, Lamarck persevera en un arduo tour de force fisiológico e intenta explicar esa peculiaridad en base a la circulación y la acumulación de los fluidos orgánicos. Sin considerar o siquiera mencionar las eventuales ventajas que, a posteriori de su aparición, esas protuberancias podrían acarrear, Lamarck se limita a considerarlas como el efecto residual de un movimiento habitual y constante que desvía el curso normal de los fluidos orgánicos. Es más: en este caso se hace particularmente patente que, para Lamarck, el comportamiento sólo cuenta en tanto que factor capaz de desencadenar o producir fenómenos fisiológicos; y es desde esa perspectiva fisiológica que a él le interesan esas peculiaridades morfológicas: lo que Lamarck quiere saber es cómo ellas se producen y no por qué es que ellas están allí.

Ante una estructura particular como el pescuezo de la jirafa o los cuernos de un toro, la pregunta lamarckiana no es ¿qué ventaja o beneficio ella trae?; sino ¿qué mecanismo fisiológico la genera? La biología de la Filosofía zoológica es una ciencia de causas próximas que actúan en y sobre el organismo individual; y, en este sentido, podemos decir que Lamarck no era ni más ni menos que un fisiólogo interesado en establecer, como dijo alguna vez Felix Le Dantec, "las leyes más generales que rigen las relaciones del funcionamiento con la construcción de las formas, de la fisiología con la morfología" (Dantec, 1915, p. 8). Sin Lamarck, pensaba Le Dantec, la fisiología estudia el funcionamiento presuponiendo una morfología dada; con Lamarck, en cambio, la propia morfología podría explicarse a partir de la fisiología. 


\section{Cuvier: FUnGIONALISMO NO ES ADAPTAGIONISMo ${ }^{6}$}

Pero, si la digresión de Lamarck sobre el pescuezo de la jirafa es la carta más alta de la lectura adaptacionista de la Filosofía zoológica, la pretensión de que, en principio, sería posible reconstruir el modo de vida de un animal extinto a partir de un conocimiento acabado de su anatomía y de su fisiología constituye, sin ninguna duda, uno de los puntos más fuertes de la lectura adaptacionista de Cuvier. Cuvier (1992 [1812], p. 100) pensaba, en efecto, que el conocimiento de las leyes de la economía orgánica podría permitirnos reconstruir con certeza geométrica todo la estructura y la organización de un animal a partir de un solo fragmento. Pero, además de eso, él también afirmaba que, como consecuencia de esa genuina reconstrucción fisiológica de los fósiles (cf. Guillo, 2003, p. 116), era posible llegar a conocer también la dieta y el modo de vida del animal extinto.

A partir de una uña o de un diente, decía Cuvier (1992 [1812], p. 98-100), calcularíamos la forma de sus extremidades y de sus mandíbulas; y esto no sólo nos permitiría conocer la forma de los intestinos del animal sino también su tipo de alimentación. Siendo el conocimiento de esa dieta lo que nos llevaría finalmente al conocimiento de sus comportamientos e instintos (cf. Caponi, 2004a, p. 190). El conocimiento de la anatomía y de la fisiología del ser extinto, según la promesa de Cuvier, nos conduciría al conocimiento de su modo de vida; y esta correlación entre modo de vida y estructura anatómica podría inclinarnos a pensar que Cuvier propiciaba, al final de cuentas, una visión próxima al adaptacionismo que más tarde Darwin iría a sostener.

Existe, con todo, una diferencia fundamental en el modo en que ambos autores ven esa correlación entre estructura y modo de vida. En la perspectiva darwiniana, la estructura anatómica es la ratio cognoscendi del modo de vida, pero este último es siempre la ratio essendi de aquella. Para Cuvier, en cambio, la estructura anatómica es, al mismo tiempo, ratio essendi y ratio cognescendi del modo de vida. La narración adaptacionista darwiniana va de los efectos a las causas; la reconstrucción cuvieriana pretendía ir siempre de las causas a los efectos. Para Cuvier, es cierto, un organismo es un sistema cuya armonía o coherencia interna, su verdadera condición de existencia, solamente puede ser cabalmente percibida y comprendida considerando su inserción en el entorno; pero su modo de insertarse en este entorno no es independiente de su propia organización interna.

No es como respuesta a un desafío del ambiente que un predador deviene un animal rápido y astuto; sino que es su propia fisiología de carnívoro la que le impone 
esas características (cf. Cuvier, 1992 [1812], p. 98). Pero, para entender este aspecto del programa de Cuvier es menester considerar que, desde su perspectiva, pensar al organismo como un sistema donde cada parte remite a otra, no significa que todas las partes posean la misma importancia. Las características de un organismo no están simplemente correlacionadas: unas son preeminentes sobre las otras y, en ese sentido, las determinan (cf. Cuvier, 1798, p. 20). Y, para Cuvier, los rasgos que definían las características fisiológicas más generales de un organismo eran dominadores sobre aquellos que definían el modo por el cual un organismo se insertaba en la economía natural.

Por eso, y como acabo de decir, esa inserción es la consecuencia, y no la causa, de esa organización; es decir, las estructuras anatómicas que definen el modo por el cual un animal se vincula a su entorno y a sus fuentes de alimento son un corolario de sus pautas más generales y fundamentales de organización (cf. Cuvier, 1817a, p. 69). Para Cuvier, hubiese podido decir Florentino Ameghino (cf. 1915 [1884], p. 145), los caracteres de organización eran siempre más importantes que los caracteres de adaptación. Gran parte de lo que hoy llamaríamos a estrategias o estructuras adaptativas eran, para Cuvier (cf. 1805, p. 57), la resultante necesaria de ciertas leyes de coexistencia que rigen la fisiología de los organismos, y no una simple respuesta a las exigencias del ambiente (cf. Caponi, 2004a, p. 191).

Además, es precisamente esa preeminencia de las coerciones organizacionales sobre los factores adaptativos la que explica el hecho de que Cuvier haya confiado en la posibilidad y en la legitimidad de reconstrucciones paleontológicas que no se apoyaban en ningún putativo conocimiento del ambiente en los cuales los seres en estudio habrían vivido. Cuvier carecía, en efecto, de cualquier cosa remotamente semejante a una paleoecología y no pretendía, ni quería, llenar ese vacío con conjeturas y especulaciones. El afamado reconstructor de mundos desaparecidos era a este respecto bastante parco; pero aún así, creía que sus reconstrucciones de fósiles eran viables y justificables a partir de las complejas leyes que regían la correlación y la subordinación de las partes. O como lo decía Littré (1997 [1834], p. 152): "todo está en la organización de los seres animados; una parte determina una otra parte; una función determina otra función" (cf. Caponi, 2004a, p. 192).

Pero función no significa aquí otra cosa que función fisiológica; y es por eso que una función puede conducir al conocimiento de otra sin que eso exija un conocimiento del ambiente. Para Cuvier la función de un órgano no era lo que Bock y Wahlert (1998) llamarían su rol biológico. La función de un órgano era para Cuvier el papel causal que ese órgano jugaba en el funcionamiento de la máquina animal (cf. Milne-Edwards, 1867, p. 12; Daudin, 1926a, p. 62-3; Mazliak, 2002, p. 20); y era esa misma noción fisiológica de función, y no a nada semejante con la idea darwiniana de adaptación, que Cuvier (cf. 1805 , p. vi) aludía cuando decía que la anatomía comparada nos permitía 
conocer la función de un órgano y de cada una de sus partes. Hay en Cuvier un marcado funcionalismo organicista que, a diferencia de Bowler (1998, p. 192), Amundson (2001, p. 3०7) y Gould (2003, p. 16), no debemos confundir con una perspectiva adaptacionista o utilitarista.

Es cierto, la aproximación entre las expresiones 'uso [usage] de un órgano' y 'función [fonction] de un órgano' que encontramos en la carta a Mertrud puede darnos la impresión de que Cuvier (cf. 1805, p. vI) esté aludiendo a alguna cosa semejante a aquello que Bock y Wahlert (cf. 1998, p. 131) describen como el rol biológico de una estructura. Pero, el hecho de que en esas mismas páginas sólo se aluda a la comparación entre estructuras anatómicas como siendo el único "método de razonar en fisiología" (Cuvier, 1805, p. vi), y no se diga nada del análisis de las condiciones de vida del organismo, nos indica que esas nociones de usage y fonction están siendo usadas en el mismo sentido en que luego podría usarlas el propio Claude Bernard. La noción de rol biológico, mientras tanto, tiene que ver con la acción o el uso de un rasgo orgánico en el curso de la historia de vida de su portador (cf. Bock \& Wahlert, 1998, p. 130); y su conocimiento exige algo que no puede hacerse en el gabinete del anatomista. "La observación del organismo viviendo naturalmente en su ambiente”, como nos dicen Bocky Wahlert (1998, p. 131), "es esencial a la descripción de un rol biológico" (cf. Caponi, 2004a, p. 183).

Así, y como ejemplo de lo que estamos diciendo, podemos citar el tratamiento que, en su Mémoire sur les céphalopodes, Cuvier le da a la tinta que pulpos, calamares y jibias expelen, según el mismo dice, "ante la menor apariencia de peligro". Esa característica es allí apuntada como una particularité remarquable de ese grupo de organismos (Cuvier, $1_{18}$ b b p. 4), pero la referencia que se hace a ese posible rol biológico es superficial, lateral. Cuvier (1817b, p. 1) alude a la cuestión en un primer parágrafo donde se enumeran algunas rarezas y singularidades de estos animales y allí nos dice que la expulsión de tinta constituye su "principal medio de defensa". Luego, retomando brevemente la cuestión, acepta la posibilidad de que esa tinta les sirva también a los cefalópodos para esconderse no solamente de sus posibles agresores sino también de sus eventuales presas. Pero, determinar hasta qué punto y en qué casos eso es efectivamente así no parece importarle mucho a Cuvier.

Así, aún citando las observaciones de Aristóteles sobre los cefalópodos, nuestro autor ni siquiera menciona el hecho de que el estagirita considere que solamente la jibia usa su tinta para esconderse. La expulsión de tinta por parte del pulpo y del calamar, según leemos en la Historia de los animales, sería un efecto del miedo y no un recurso protector; y Aristóteles no se apoya para decir esto en ninguna especulación psicológica, sino en un análisis del modo en que la jibia se comportaría una vez que la tinta salió de su cuerpo (Aristóteles, 1994, 621b, p. $5^{19}$ de nuestra edición). Este animal, a diferencia del pulpo y del calamar, según Aristóteles dice, retornaría hacia la mancha 
de tinta aprovechándola como escondite; y claro que no se trata aquí de saber quién tenía razón, sino de percibir como la perspectiva de Cuvier es indiferente a un tema que, de hecho, daría mucho para discutir.

Es significativo, además, que el joven naturalista supernumerario del HMS Beagle ya se haya mostrado más atento a este tipo de cuestiones que Cuvier. En el primer capítulo de su Voyage of the Beagle, Darwin (cf. 1902 [1845], p.18) dice haber dedicado largas horas de su estancia en Cabo Verde al estudio del comportamiento de los pulpos y su conclusión es que, por lo menos esos pulpos, expulsan su tinta siempre que realizan traslaciones rápidas. Como vemos, su interpretación de ese comportamiento es diferente de la de Aristóteles y sería oficio de un naturalista, en el sentido que hoy damos al término, el determinar quién de los dos tiene razón, si ambos están equivocados o si los pulpos del Egeo se comportan de un modo diferente a los de la Isla de Santiago.

Pero estos asuntos no parecían importarle demasiado a Cuvier. Para él, sin duda, tanto la naturaleza y la composición del liquido segregado (Cuvier, 1817b, p. 4-5), como la individualización y la descripción del órgano que lo produce y lo contiene (Cuvier, 1817b, p. 31) eran cuestiones mucho más importantes. Asuntos todos que, por otra parte, se pueden estudiar lejos de la playa: sobre el frío mármol de la mesa de disección, en Paris. ${ }^{7}$ Pero esto es comprensible: lo que para Cuvier (1817b, p. 42) está en juego es la caracterización de la organización de los cefalópodos: sus condiciones de existencia y no sus condiciones de vida; ${ }^{\mathbf{8}}$ la función de sus partes y no su rol biológico. Siendo en ese contexto en donde se puede apuntar que existen diferencias anatómicas entre las distintas especies de pulpo sin intentar vincular esas diferencias con el modo de vida de estos animales; $y$, sobre todo, sin intentar vincularlas con los otros seres vivos que los rodean (cf. Cuvier, 1817b, p. ๆ).

Pero así, siguiéndose ese interés fundamentalmente fisiológico, se deja de lado precisamente el tópico que a Darwin (cf. 1859, p. 3-4) iría a parecerle central: el de los múltiples detalles, generalmente contingentes desde una perspectiva fisiológica, que

\footnotetext{
7 Cuvier, claro, fue siempre un naturalista de museo o de gabinete; pero, sin ser un naturalista de campo, Cuvier tampoco era un naturalista de escritorio o de biblioteca. En la historia natural de inicios del xIx, el gabinete de anatomía comparada no era más ajeno a la experiencia que el propio laboratorio de fisiología experimental.

8 Por condiciones de existencia, conforme Russell (1916, p. 34) lo apuntó, Cuvier "entendía algo muy diferente de lo que hoy es comúnmente entendido". Atento al hecho de que todas las partes de un cuerpo organizado ejercen "una acción recíproca las unas sobre las otras y concurren a un fin común que es la manutención de la vida" (Cuvier, 1798, p. 5), él consideraba que "la verdadera condición de existencia de un ser vivo, y parte de su definición esencial, es que sus partes trabajen juntas para el bien del todo" (Russell, 1916, p. 34). Por eso, sus indagaciones se centraban, casi exclusivamente, "sobre las adaptaciones de la función y el órgano dentro de la criatura viviente" (Russell, 1916, p. 34). Para nosotros, como para Darwin (cf. 1859, p. 127), mientras tanto, las condiciones de existencia se homologan a las conditions of life; $y$ éstas tienen que ver, no con la coordinación de las partes en la constitución del todo, sino más bien con las contingencias de la lucha por la supervivencia (analicé esta cuestión en Caponi, 2003).
} 
nos revelan las complejas tramas de relaciones ecológicas que los seres vivos guardan entre sí (cf. Guillo, 2003, p. 229). La idea de que la estructura de cada ser orgánico está indisolublemente relacionada con la estructura "de todos los otros seres orgánicos con los cuales entra en competición por comida o residencia, o de los cuales tiene que escapar o a los cuales tiene que apresar" (Darwin, 1859, p. 77) no es una tesis cuvieriana (cf. Caponi, 2004c, p. 242); y, por mucho que lo busquemos, poco o nada encontraremos en el corpus cuvieriano que nos recuerde a los pormenorizados análisis de Darwin (cf. 1877) sobre las variados artilugios con que las orquídeas suelen facilitar su fecundación por parte de un insecto.

\section{Cuestiones de detalle}

De hecho, a la hora de explicar variaciones estructurales secundarias y de poca relevancia organizacional, Cuvier prefería apelar a factores causales inmediatos antes que a la posible utilidad de esas variaciones; y, en este sentido, su modo de razonar también se aproxima al de Buffon (cf. Flourens, 185o, p. 91). Así, en el Discours préliminaire a las recherches sur les ossements fossiles de quadrupèdes, la variación intra-específica es explicada como el efecto de factores ambientales tales como la temperatura, la luminosidad, la composición y la cantidad de las substancias que componen la dieta del organismo; factores estos que actuarían directamente sobre los procesos fisiológicos que ocurren en el organismo individual. Siendo, claro, "los caracteres más superficiales" los que más variarían en virtud de la intensidad de tales agentes: "el color debe mucho a la luz, el espesor del pelo al calor" y "el tamaño a la abundancia del alimento" (Cuvier, 1992 [1812], p. 113; 1798, p. 10-1).9

Según esta tesis de Cuvier (1992 [1812], p. 114), “los elefantes serán mayores en tal o cual selva" en virtud de la disponibilidad de alimentos y los mismos "tendrán los colmillos un poco más largos en los lugares donde el alimento sea más favorable a la formación de la materia del marfil”. La hipótesis de que ese tamaño pueda variar justamente en virtud de su capacidad para operar como medio de defensa o lucha contra predadores o congéneres no es siquiera mencionada: está fuera de cuestión; y lo que se dice del tamaño de los colmillos de los elefantes vale, según Cuvier, para el tamaño de los cuernos de renos y ciervos. Éstos variaran en virtud de los elementos que integran la dieta de estos animales y no en virtud de los desafíos impuestos por el ambiente

9 La mayor o menor abundancia de alimentos es también citada por Humboldt (cf. 1811, p. 40) para explicar las diferencias de tamaño que existirían entre los cóndores de Chile y Perú y aquellos que habitan las regiones más tórridas de Sudamérica. 
(Cuvier, 1992 [1812], p. 114); y es de suponer, incluso, que esas coloraciones que Henry Bates, Alfred Russell Wallace y Fritz Müller nos enseñaron a considerar, darwiniamente, como ejemplos de mimetismo (cf. Gayon, 1992, p. 190-203) serían explicadas por Cuvier como una consecuencia de la dieta o por el efecto directo de la luz sobre el cuerpo de los organismos implicados. ${ }^{10}$

Donde siguiendo a Darwin aprenderíamos a ver recursos adaptativos o roles biológicos, Cuvier, a la manera de Buffon, simplemente veía, o bien el efecto inmediato de la calidad y la cantidad de las moléculas que el organismo asimilaba por respiración y por alimentación, o bien la incidencia directa de un factor físico como la luz o la temperatura. O dicho de otro modo: donde Darwin vendría a denunciar las marcas que la lucha por la existencia deja en las estructuras biológicas, Cuvier (cf. 1798, p. 10), al igual que Buffon, sólo veía las marcas que los diferentes agentes físicos dejaban en los perfiles de los organismos; y ésa era, como ya dije, la posición o la perspectiva ciertamente prevaleciente entre los naturalistas de la primera mitad del siglo XIX.

Por eso, y contrariamente a lo que hoy pueda parecernos, lo cierto es que, en 1858, la interpretación adaptacionista o utilitaria de las estructuras biológicas y, sobre todo, de los más mínimos detalles morfológicos, propugnada por Darwin y Wallace, estaba lejos de ser obvia y aceptada. No sólo la explicación por selección natural del surgimiento de esas estructuras y esos detalles era cuestionada; sino que hasta la mera idea de que los mismos fuesen realmente útiles también era ampliamente resistida. Tal es así que Darwin se vio obligado a defender explícitamente esa suposición tanto en la última sección del capítulo sexto de la primera edición del Origen (cf. Darwin, 1859, p. 194-203) como en gran parte del capítulo sobre "Objeciones misceláneas a la teoría de la selección natural" que fue agregado en ediciones posteriores de esa misma obra (cf. Darwin, 1998 [1872], p. 266 ss.).

De hecho, conforme la opinión del propio Wallace (1891, p. 35), ese principio de utilidad según el cual "ningún órgano especial, ninguna forma distintiva, ninguna peculiaridad en los instintos o hábitos, ninguna relación entre especies o grupo de especies, podría existir sino fuese ahora o no hubiese sido alguna vez útil para los individuos o para las razas que los poseen" era una contribución original de Darwin que se derivaba directamente del principio de selección natural; y ésa es una forma de reconocer el hecho de que esa omnipresente utilidad no pertenecía, como en cambio sí ocu-

10 De hecho, las teorías que Wallace (cf. 1891, p. 36) enumera como siendo posibles alternativas a la explicación darwiniana de las coloraciones protectivas son dos: una es la teológica y la otra es justamente aquella que apelaba a "la acción directa del clima, del suelo o de la comida"; y esta última es la única hipótesis que Darwin (1977 [1863], p. 90) considera como una posible alternativa a la explicación seleccionista de la coloración de ciertas mariposas que había sido propuesta por Bates. 
rría, por ejemplo, con las afinidades morfológicas, al conjunto de esas grandes evidencias ya antes reconocidas por la historia natural y que Darwin proponía explicar por su teoría de la descendencia con modificaciones (cf. Gayon, 1992, p. 190).

Es innegable, claro, que esa adecuación global de cada ser vivo a aquello que Darwin y Wallace entienden por condiciones de existencia era parte integrante, en cierto sentido, de ese gran conjunto de evidencias ya reconocidas que la teoría de la selección natural tendría el alegado mérito de explicar (cf. Darwin, 1859, p. 206); y algo semejante puede decirse de la presencia en los seres vivos de estructuras tan obviamente útiles como es el caso del pico del pájaro carpintero (cf. Darwin, 1859, p. 3). Pero de ahí a suponer que, dejando de lado la innegable acción directa de ciertos factores físicos, "todo detalle de estructura en cualquier criatura viviente [...] debe ser visto, o como habiendo tenido algún uso especial para una forma ancestral, o como teniendo ahora un uso especial para los descendientes de dicha forma" (Darwin, 1859, p. 200) hay todavía un gran paso a dar; y ese paso no es otro que ese corolario de la teoría de la selección natural que Wallace llamó principio de utilidad.

Éste, conforme Wallace (1891, p.36) lo consignaba, opera como “una clave que podemos seguir en el estudio de innúmeros fenómenos recónditos y que nos conduce a procurar un significado y un propósito para muchos caracteres definidos", llamándonos la atención sobre "minucias que de otro modo casi seguramente pasaríamos por alto considerándolas como insignificantes o como carentes de importancia”; ${ }^{11}$ y es desde esa perspectiva que detalles morfológica y fisiológicamente secundarios como la coloración pudieron pasar a ser considerados como algo más que el simple efecto accidental de la incidencia sobre el organismo individual de factores físicos tales como la dieta, el clima o la luminosidad.

Es más: el hecho de que halla sido Henry Bates el creador del término y del concepto de mimetismo y la circunstancia de que ni siquiera el propio Darwin haya considerado ese tipo de hechos en su primera edición del Origen de las especies (cf. Gayon, 1992, p. 190) constituyen indicios adicionales respecto de lo poco obvias que resultaban esas interpretaciones utilitarias de los perfiles orgánicos que la teoría de la selección natural venía a propiciar. Claramente, la interpretación utilitaria de la coloración no preexiste a la teoría de la selección natural; la eventual conveniencia adaptativa de ciertos colores no constituye un hecho reconocido y a la espera de explicación: esa conveniencia sólo es sospechada o reconocida en base a la propia teoría en cuestión

11 Esta formulación de Wallace tiene también el merito de presentar al principio de utilidad como siendo una regla heurística que nos dispone a una búsqueda empírica del carácter utilitario de estructuras orgánicas que, en una primera aproximación, podrían parecer como desprovistas de todo valor adaptativo. Un tipo de indagación empírica que, por lo general, no encontramos en las reflexiones de la teología natural. 
(cf. Gayon, 1992, p. 190). Antes de ella, nadie, ni siquiera el propio Darwin, parecía considerar las coloraciones desde esa perspectiva. ${ }^{\mathbf{1 2}}$

Así, aun habiendo constatado el predominio de la capa gateada entre los caballos americanos e incluso reconociendo la similitud de ese color con el que presentan la mayor parte de los animales salvajes, Humboldt (cf. 1991b [1802], p. 238) no llega siquiera a percibir que esa coloración presenta cierta semejanza con las tonalidades de los arenales y pajonales de las regiones del nuevo mundo en las que tales caballos prosperaron. En cambio, ya en tiempos definitivamente darwinianos, Emilio Solanet (1971, p. 21) no duda en atribuir un valor mimético a ese color, considerándolo, específicamente, como "un medio más para defender a los potrillos de la voracidad de los perros cimarrones y del puma"; ${ }^{3}$ y lo que ocurrió con las diversas coloraciones de los seres vivos, ocurrió también con otros muchos detalles morfológicamente accidentales que, como las caprichosas peculiaridades morfológicas de las orquídeas, de pronto la teoría de la selección natural ponía bajo una nueva luz enseñándonos a verlos como artilugios adaptativos.

12 Un indicio de lo poco obvias que podían resultar las explicaciones utilitarias o adaptacionistas de esas coloraciones que hoy consideramos miméticas y de la marcada preferencia que los biólogos podían tener por explicaciones que apelasen a posibles causas próximas, eventualmente involucradas en esos fenómenos, puede ser encontrado en la resistencia que esas explicaciones continuaron suscitando después del advenimiento del darwinismo; y un ejemplo de esto lo encontramos en un pasaje del discurso pronunciado por E. Roquette Pinto en Blumenau, el 20 de mayo de 1929, cuando de la inauguración de una estatua de Fritz Müller. En esa oportunidad, que ciertamente hubiese sido más propicia al encomio que a la critica severa, este orador, seguramente más amigo de la verdad que de Fritz Müller y profundamente imbuido del clima intelectual de esos años de eclipse del darwinismo, se sintió obligado, o autorizado, a decir que "todas las viejas explicaciones del mimetismo propuestas en los tiempos heroicos del transformismo" habían casi perdido su valor porque, en ese momento, ya nadie aceptaba explicaciones teleológicas (o sea, utilitarias) y por eso las teorías del mimetismo, sean ellas de Darwin, de Wallace, de Bates o de Müller, ya no eran “mais o que dantes foram". Para el Doctor Roquette Pinto, por lo menos, una explicación que apelase a factores puramente hormonales sería suficiente y más satisfactoria (más seria, más científica) que la propuesta por Müller (Pinto, 2000 [1929], p. 41). Podrá ser un anacronismo, pero es difícil resistirse a la tentación de observar que, en aquella seguramente tibia tarde de otoño de 1929, Roquete, como se dice en Brasil, perdeu a oportunidade de ficar calado. Lo cierto, sin embargo, es que el comentario de este biólogo sobre la obra de Müller muestra que la autoevidencia de la explicación utilitaria está lejos de ser real: aún setenta años después de la publicación del Origen la misma podía ser todavía recusada. No debe asombrarnos, por lo tanto, que Cuvier y sus contemporáneos no la hayan tenido siquiera en consideración: como Roquete, ellos también tenían buenas razones para no hacerlo; y como Roquete, ellos también procuraban explicaciones fisiológicas, por causas próximas, para dar cuenta de cualquier coloración.

13 No deja de ser interesante que Solanet también cite como evidencia a favor de su hipótesis el hecho de que los gauchos, supuestamente, ya habían reconocido de algún modo la utilidad de esa semejanza entre el color de los gateados y la tonalidad general del paisaje pampeano o serrano y por eso, en la guerra, preferían a los caballos de ese pelo: éstos, según la idea que Solanet le atribuye a nuestros gauchos, "llamarían menos la atención de las fuerzas enemigas". 


\section{ENTORNo ATMOSFÉRICo vS ENTORNO BIOLÓGIGO}

En general, salvo observaciones aisladas que pueden ser ciertamente encontradas en los trabajos de algunos naturalistas viajeros, ${ }^{\mathbf{1 4}}$ en lo atinente a la cuestión planteada por la correlación existente entre los perfiles orgánicos y las condiciones ambientales en las que se desarrolla la vida de los diferentes seres vivos, la historia natural que precede inmediatamente a la revolución darwiniana no iba nunca mucho más allá de esa tematización del amoldamiento de los organismos a factores como el clima y la dieta que ya encontramos en Buffon. Tal el caso, incluso, de Isidore Geoffroy SaintHilaire: un autor cronológicamente contemporáneo de Darwin, pero definitivamente predarwiniano, si considerado desde una perspectiva epistemológica. ${ }^{15}$

En efecto, según las teorías sobre la aclimatación por él defendidas, las diferentes especies o razas pueden acomodarse y prosperar en distintas regiones del globo, o pueden soportar cambios climáticos de gran escala, en la medida en que las mismas son capaces de modificarse en virtud de alteraciones hereditariamente acumulables que los propios factores climáticos desencadenan en los organismos individuales (cf. Saint-Hilaire, 1861, p. 142 ss.). Es decir: los organismos individuales responden a los cambios climáticos mediante alteraciones fisiológicas que les permiten habituarse a las nuevas condiciones de vida y esos cambios se van acumulando hereditariamente modificando así, siempre dentro de ciertos limites, ${ }^{\mathbf{6}}$ los perfiles de la raza o de la es-

\footnotetext{
14 Un ejemplo de esto lo podemos tal vez encontrar en aquel pasaje de su Viaje a las regiones equinocciales del nuevo continente en el que Humboldt (1991a [1802], p. 99) vincula la diferencia en los picos del Guácharo y el Chotacabras con diferencias en sus modos de vida. Me parece, de todos modos, que Humboldt razona ahí a la Cuvier: presuponiendo que la organización es la que determina aspectos como la dieta y el comportamiento; y no a la inversa. Lo cierto, por otra parte, es que esas correlaciones no abundan en los escritos de Humboldt como de hecho tampoco abundan en el joven Darwin de la primera edición del Viaje del Beagle (Darwin, 1989 [1839]). Allí, en el capitulo dedicado a las Galápagos, las diferencias entre los picos de las diferentes especies de pinzones son sumariamente registradas sin hacer ninguna referencia a la relación que tales diferencias podrían tener con las condiciones de vida de cada una de dichas especies. De hecho, lo único que Darwin (1989 [1839], p. 276) dice al respecto es que la mayoría de esas especies poseen hábitos muy semejantes; y Darwin habla aquí de especies diferentes porque, ya antes, en 1837, él había sido advertido por John Gould sobre el hecho de que los especimenes de pinzones traídos desde las Galápagos pertenecían a trece especies distintas (cf. Darwin, 1977 [1837], p. 4, ; Weiner, 1995, p. 37; Desmond \& Moore, 2000 , p. 238). Es de observarse, mientras tanto, que en la edición del Viaje del Beagle de 1845 las cosas cambian un poco y Darwin (1902 [1845], p. 140) se atreve a decir ahí que "al considerar esta gradación y diversidad de conformaciones en un grupito de pájaros tan próximos unos a otros, podría creerse que, en virtud de una pobreza original de pájaros en ese archipiélago, se había modificado una sola especie para llegar a fines diferentes". Un pequeño añadido tipográfico que ya preanuncia una gigantesca revolución epistemológica.

15 Isidore Geoffroy Saint-Hilaire, hijo de Etienne, murió en 1861 a los cincuenta y seis años; y su obra no llegó a sentir el impacto de la revolución darwiniana: sus trabajos pueden ser por eso considerados todavía como representativos de la historia natural predarwiniana.

16 Más prudente que su padre, Isidore propugnaba sólo una teoría de la variabilidad limitada del tipo (cf. SaintHilaire, 1859, p. 434; Osborne, 1994, p. 68 ss.).
} 
pecie sometida a nuevas condiciones. No existía en esas teorías aclimatacionistas ninguna referencia a los desafíos que los seres vivos pueden plantearse los unos a los otros; ni existía allí tampoco ninguna referencia a las particularidades morfológicas que pueden servir como respuestas a esos desafíos.

Los cambios climáticos considerados por Isidore Geoffroy Saint-Hilaire (1861, p. 146) no eran otra cosa que el "conjunto de las variaciones atmosféricas que afectan nuestros órganos de una manera sensible"; y esto incluía variables como "la temperatura, la humedad, los cambios en la presión barométrica, la calma de la atmósfera, los vientos, la pureza del aire, o la presencia de miasmas más o menos deletéreas y, en fin, el grado habitual de transparencia y serenidad del cielo". Nada allí remitía a factores específicamente biológicos que pudiesen propiciar y exigir cambios morfológicos o etológicos en las diferentes especies; y era contra ese tipo de limitaciones, presentes también en las perspectivas de Cuvier y Buffon, que Darwin (1859, p. 3) se volvía cuando decía que al considerar a las "condiciones externas tales como clima, comida etc., como si fuesen las únicas causas de variación”, los naturalistas no conseguían explicar cosas tales como "la estructura del pájaro carpintero, con sus pies, cola y lengua tan admirablemente adaptadas a capturar insectos bajo la corteza de los árboles”.

Lo cierto, sin embargo, es que, para poder explicar el surgimiento de esa complejidad estructural desde una perspectiva naturalista, no teológica, era preciso superar lo que hoy, a posteriori, cabe considerar como una limitación epistemológica común a toda la historia natural predarwiniana. Aludo a esa perspectiva organísmica o fisiológica que llevaba a considerar al viviente individual como locus privilegiado y hasta exclusivo del fenómeno biológico. Es que, en ese contexto, difícilmente se puede ir más allá del tratamiento de cambios corporales pasibles de ser plausiblemente explicados, por lo menos a primera vista, como el efecto de diversos factores actuantes sobre el organismo individual como lo son las condiciones atmosféricas en general, la alimentación o incluso el uso y el desuso de ciertos órganos. ${ }^{17}$ Siendo la generalizada y por mucho tiempo nunca cuestionada idea de la trasmisión hereditaria de lo adquirido lo que permitía entender la acumulación, más o menos limitada, y la fijación de esos cambios dentro del grupo o especie de organismos en consideración. ${ }^{\mathbf{1 8}}$

17 Lamarck apela al par uso-desuso justamente procurando dar con una explicación que, sin salirse de la perspectiva organísmica, pudiese dar cuentas de ciertos cambios morfológicos que no podían ser considerados como efecto directo de la dieta o de factores atmosféricos.

18 La transmisión de lo adquirido nunca fue una tesis privativa o peculiar de Lamarck. (cf. Burkhardt, 1995, p. 179). Cuando él apela a ella para argumentar a favor de su transformismo, la misma era una idea generalmente aceptada; como además siempre lo había sido y como incluso lo seguiría siendo por medio siglo más. Sobre lo que podía haber diferencias era sobre la posible acumulación de esos cambios hereditarios: para los autores fijistas como Cuvier esa acumulación no podía ir más allá de cierto limite (cf. Pichot, 1999, p. 252). 
De hecho, para que esa limitación epistemológica fuese revertida, pero sin ir más allá de los limites de lo que podía ser considerado una ciencia natural, ${ }^{19}$ se hizo necesario acceder a la perspectiva poblacional presupuesta en el darwinismo: ${ }^{20}$ la población es un sistema biológico cuya capacidad de registrar exigencias ambientales y responder a las mismas es mucho menos limitada que la de los propios organismos individuales. El pico de un pájaro individual no puede modificarse en vistas a la mejor explotación de una nueva fuente de alimento; pero si nos remitimos al plano poblacional esa modificación sí es pensable y explicable, no por una improbable reacción fisiológica supuestamente análoga al incremento de la transpiración en un día de calor, sino por la mediación de ese fenómeno poblacional que es la selección natural. Siendo esa misma perspectiva poblacional la única que puede hacernos pensar una coloración en términos utilitarios y no como el mero efecto de factores físicos inmediatos que actuarían en o sobre los organismos individuales. ${ }^{21}$

Es de notarse, por otro lado, que en lo atinente a la relación entre el ambiente y las modificaciones o peculiaridades morfológicas de los seres vivos, la diferencia entre Darwin y el punto de vista defendido tanto por Isidore Geoffroy de Saint-Hilaire como por Buffon y Cuvier pasaba por el mismo meridiano epistemológico por el que también pasaba su diferencia con aquellos otros naturalistas que, siguiendo en eso también a Buffon (1761, p. 2), tendían a explicar la distribución geográfica de los seres vivos básicamente en virtud de factores climáticos o, más en general, atmosféricos. ${ }^{22}$ Tal el caso paradigmático e insigne, claro, de Alexander Von Humboldt (cf. Radl, 1931, p. 262; Canguilhem, 1965, p. 139; Limoges, 1976, p. 58; Rehbock, 1983, p. 152; Acot, 1988, p. 26; Drouin, 1993, p. 68; 1997, p. 496; 2001, p. 849; Bowler, 1998, p. 149): mientras éste asociaba la distribución geográfica de los seres vivos con bandas isotérmicas e isobáricas (cf. Humboldt, 1977 [1845], p.72; Papavero et al., 1997, p. 183; Helferich, 2005, p. 118); Darwin (1859, p. 14,0) sostenía "que las especies en estado de naturaleza están estrictamente limitadas a sus áreas por la competencia de otros seres orgánicos, tanto más que por la adaptación a sus climas particulares”.

19 En una biología de causas próximas que actúan en y sobre el organismo individual, es difícil explicar el surgimiento de estructuras adaptadas, funcional o ecológicamente, sin romper el cerco de la ciencia apelando a una misteriosa capacidad de la materia orgánica para autodeterminarse inconscientemente con adecuación a fines, como en Schopenhauer (cf. 1947 [1857], p. 74 ss.), o sin recurrir al más consabido designio de un artífice supremo. No puede asombrarnos, por eso, que, antes del darwinismo, la visión utilitaria de la estructuras orgánicas sólo haya prosperado al abrigo de un pensamiento teológico o metafísico.

20 En Caponi 2005, desarrollé con mayor detallé la oposición entre la perspectiva poblacional darwiniana y la perspectiva organísmica.

21 Basándome en ciertas ideas de Dennett, en Caponi 2002 me permití sostener la tesis de que el darwinismo nos presenta a los poblaciones como constituyendo sistemas cognitivos.

22 Sobre este aspecto de la biogeografía de Buffon, cf. Flourens, $185^{\circ}$, p. 152-4. 
Es verdad: la temperatura no era ciertamente el único factor considerado por Humboldt; para él, otros factores físicos tales como la presión atmosférica, la humedad y la tensión eléctrica también incidían en la distribución de los vegetales (cf. Humboldt, 1805 , p. 14). No cabe duda, sin embargo, que, desde su punto de vista, la temperatura jugaba ahí un papel central. En su opinión, "a pesar de la influencia que la presión del aire y la extinción más o menos grande de la luz ejercen sobre las funciones vitales de las plantas, es con todo el calor desigualmente distribuido entre las distintas partes del año, lo que ha de considerarse como el estímulo más poderoso de la vegetación" (Humboldt, 1991a [1802], p. 346). Por otro lado, si bien es cierto que esa asociación entre el clima y la distribución geográfica de los seres vivos se refería fundamentalmente a las plantas (cf. Humboldt, $180_{5}$ ), tampoco deja por eso de ser verdad que, aunque con algunas dudas o restricciones, Humboldt también pretendía extender esa correlación a los animales.

Éstos, según leemos en su Ensayo sobre la historia natural del cóndor, también "siguen, aunque ciertamente menos que las plantas, esa identidad de formas en sitios que están alejados los unos de los otros, pero que gozan de un clima análogo"; y esta suposición hace que Humboldt (1811, p. 38) llegue a plantearse la siguiente pregunta: “ ¿Si, en el medio de las inmensas planicies del valle del Amazonas, una montaña aislada se elevase hasta las regiones heladas, esa montaña estaría habitada por cóndores, guanacos o vicuñas?" Prudente, él deja la cuestión sin responder; es evidente, sin embargo, que la misma sólo fue planteada para sugerir la plausibilidad de que esa correlación entre clima y fauna efectivamente se cumpla por lo menos con cierta aproximación.

Es menester reconocer, sin embargo, que un observador tan agudo como Humboldt no podía dejar de percibir que, en algunas ocasiones por lo menos, las variables climáticas eran insuficientes para explicar la distribución geográfica de los seres vivos. Tal el caso de lo que ocurría con la distribución geográfica de los molestos y omnipresentes mosquitos: la misma, según también leemos en el Viaje a las regiones equinocciales del Nuevo Mundo, no parece "depender únicamente del calor del clima, del exceso de humedad o de lo cuajado de las selvas, sino de circunstancias locales difíciles de precisar" (Humboldt, 1991c [1802], p. 69); y esas circunstancias, podría decir Darwin, sólo serían difíciles de precisar porque no se le estaría dando la debida atención a los factores específicamente biológicos que estarían incidiendo en dicha distribución.

Para Darwin (1859, p. 139), en efecto, quienes consideraban "el clima y las condiciones físicas de vida como los elementos esencialmente importantes de distribución de los seres orgánicos" cometían dos errores: el primero consistía en sobrestimar "el grado de adaptación de las especies a los climas en que viven"; y el segundo consistía en ignorar que "el área ocupada por los individuos de una especie en un país 
cualquiera no depende de modo alguno exclusivamente del cambio gradual e insensible de las condiciones físicas, sino que depende, en gran parte, de la presencia de otras especies a costa de las cuales vive, o por las que es destruida o con las que entra en competencia" (Darwin, 1859, p. 175).

Así, en contra del primer error, Darwin (cf. 1859, p. 140) citaba el ejemplo de plantas y animales que resisten con perfecta salud cuando son trasladados a países de climas muy diferentes a los de sus países de origen; y en contra del segundo aludía, por ejemplo, al número prodigioso de plantas que crecían en los jardines de Inglaterra soportando perfectamente el clima allí imperante pero sin llegar nunca a naturalizarse por no conseguir, ni competir con las plantas nativas, ni tampoco resistirse a la destrucción a la que las sometían los animales nativos (cf. Darwin, 1859, p. 69). Tal el caso también, podría incluso haber dicho Darwin, de la distribución del ganado europeo en Sudamérica: la misma, tal como él mismo observó, no depende tanto de los rigores del clima tórrido como de la capacidad "de resistir el ataque de los insectos" que puedan tener las diferentes variedades de vacas, caballos, ovejas o cabras (Darwin, 1859, p. 72, 195).

No se trataba, claro, de poner en duda que los factores climáticos jugasen un papel importante en la distribución biogeográfica, sino de reconocer que se trataba de un papel indirecto, siempre mediado por relaciones específicamente biológicas (cf. Darwin, 1859, p. 175); y esas relaciones condicionaban la distribución geográfica de las especies de un modo más inmediato que los factores climáticos. 23 "Alos ojos de Darwin", lo decía muy bien Georges Canguilhem (1965, p. 137), "la relación biológica fundamental es la relación entre el viviente y otros vivientes": ella "supera la relación entre el viviente y el medio, concebido como conjunto de fuerzas físicas”. De modo tal que hasta podría afirmarse que "el primer medio en el cual vive un organismo es un entorno de vivientes que para él son sus enemigos o aliados, presas o depredadores"; y en ese medio, en lugar de ser consideradas como meras marcas de fenómenos físicos, las variaciones de orden morfológico pueden ser pensadas “como ventajas y desventajas”.

23 Me parece oportuno aclarar, sin embargo, que cuando en su capítulo sobre "Distribución geográfica”, Darwin (1859, p. 346) dice que "ni la semejanza ni la desemejanza de los habitantes de varias regiones pueden explicarse totalmente por las condiciones climáticas u otras condiciones físicas”, él no está aludiendo tanto a esos factores ecológicos que aquí estamos destacando sino que está pretendiendo referirse a otros factores como la existencia o inexistencia de barreras naturales que puedan imposibilitar migraciones o la vinculación genealógica que puede existir entre ciertas especies que habitan una región. Factores históricos todos estos que, dígase de paso, tampoco fueron considerados por Humboldt (cf. Radl, 1931, p. 262). Así, aun habiendo observado que en la Silla de Caracas también puede encontrarse cierto vegetal, la befaria, que crece, a doscientas leguas de distancia, en las laderas de las montañas del reino de la Nueva Granada (Humboldt, 1991a [1802], p. 347), Humboldt (1811, p. 38) explícitamente se recusa a preguntarse como esa planta pudo llegar tan lejos porque "el primer origen de las cosas no puede ser ni un problema de historia, ni un objeto de investigación para un naturalista" (cf. Humboldt, 1991a [1802], p. 348). Para él basta apuntar, en cambio, que esas dos regiones presentan un clima lo suficientemente frío como para 


\section{Del EQUilibrio NATURAL A LA LUGHA POR LA EXISTENGIA}

Pero, para que las variaciones morfológicas puedan ser pensadas como ventajas o desventajas en un mundo de muchos enemigos y algunos pocos aliados, era menester que se operase una alteración realmente radical en nuestro modo de ver a la naturaleza y al lugar de los diferentes seres vivos dentro de ella; y esa alteración tiene que ver con la debacle de la idea clásica de economía natural clara y explícitamente sostenida por Linneo, pero presente de un modo u otro en toda la historia natural predarwiniana (cf. Limoges, 1972, p. 9 ss.; Mayr, 1992, p. 87 ss.; Bowler, 1998, p. 123 ss.). La perspectiva darwiniana presupone, en efecto, el abandono de esa idea (Limoges, 1976, p. 77 ss.); y, aunque a primera vista pueda parecer paradójico, es precisamente eso lo que conduce a la recuperación de la temática de los artilugios adaptativos que Wallace explicita en el principio de utilidad. Es que, si ya no puede darse por descontado que la naturaleza esté siempre en un equilibrio capaz de garantizar la perpetuación de todas las especies por un juego de complejas relaciones de mutua solidaridad; entonces la cuestión de cómo los diferentes seres vivos se las arreglan para sobrevivir no puede ser ya dejada de lado como de hecho ocurría en la historia natural de Lamarck, de Cuvier, de Humboldt y de Etienne e Isidore Geoffroy Saint-Hilaire. Si esa supervivencia ya no se supone desde el inicio garantizada, entonces es necesario volver a discutir cómo es que la misma es conquistada y preservada.

Esto, sin embargo, constituye una recuperación sólo aparente o, por lo menos, superficial, de la temática teológica; porque, como es obvio, ese retorno a un interés por las relaciones existentes entre las peculiaridades morfológicas de los seres vivos y sus condiciones de vida, obedece a motivos totalmente diferentes y, en definitiva, opuestos de aquellos que inspiraban a las reflexiones de Ray, de Linneo y de Paley. Éstas eran siempre explicita o implícitamente tributarias de un cierto mutualismo providencial según el cual los organismos no sólo presentan características que les permiten perpetuarse y sostenerse en las condiciones que les fueron dadas por el creador; sino que, además y sobre todo, los mismos "existen tal cual son en función de los otros organismos” (Limoges, 1972, nota 55a; Gedner, 1972 [1752]).

De hecho, pese al reconocimiento de que animales y plantas están dotados de recursos que les permiten propagarse y conservarse enfrentando las acciones destructivas de aquellos otros seres vivos que de ellos se alimentan (Biberg, 1972 [1749]),

posibilitar el crecimiento de esa planta. Reconoce Humboldt (1991a [1802], p. 345), no obstante, que "por más que la razón interdiga al hombre las hipótesis sobre el origen de las cosas, no dejamos de atormentarnos por esos problemas insolubles de la distribución de los seres". Fue, sin embargo, ese mismo tormento el que llevó a Darwin a dar con una solución para esos y otros problemas putativamente insolubles; y hasta puede decirse que, en cierto sentido, las anomalías o perplejidades de la biogeografía humboldtiana son los puntos de partida de la revolución darwiniana. 
la concepción clásica de la economía natural se basaba en el presupuesto que todos los seres vivos, presas o predadores, "no existen para ellos mismos sino para los otros" (Wilke, 1972 [1760], p. 119); y así, más allá de una primera apariencia, esos recursos para la propagación, la conservación y la destrucción sirven, en última instancia, no a una cruel guerra de todos contra todos, sino a la propia realización y manutención de un equilibrio natural que garantiza y exige la subsistencia de todas las especies creadas (Gedner, 1972 [1752], p. 165).

En el marco de ese mutualismo providencial, la razón última de la existencia de un ser vivo, y de cualquiera de sus atributos, residirá en la contribución que la existencia de ese ser pueda hacer para la manutención de un orden natural; ${ }^{\mathbf{2 4}}$ y es ahí precisamente en donde radica una de las diferencias más notorias entre el punto de vista sostenido por Darwin y aquel sostenido por Linneo y por Paley. ${ }^{25}$ Para Darwin, cada especie existe por cuenta, riesgo y beneficio propio; y no tiene ningún sentido preguntarse por su contribución o papel en la economía de la naturaleza. Así, al analizar las particularidades morfológicas o etológicas de un ser vivo, lo único que nos habrá de interesar es la contribución que ellas puedan hacer, o que puedan haber hecho, para la supervivencia de ese ser; y ahí estará la razón última de su existencia. En el darwinismo, el mutualismo sólo puede ser una apariencia o un subterfugio; y por eso el propio Darwin (1859, p. 201) decía que, "si se pudiese probar que cualquier parte de la estructura de una especie cualquiera ha sido formada para el bien exclusivo de otras especies, esto aniquilaría mi teoría porque una cosa semejante no podría haber sido producida por la selección natural".

Por otro lado, en la perspectiva de Darwin y Wallace, los seres vivos no tienen posiciones y funciones preasignadas en una economía natural estática y estable. Lejos de eso, esos seres vivos están condenados a tener que conquistar y defender permanentemente su lugar en un mundo que puede muy bien seguir sin ellos y cuyas exigencias cambian a cada momento. Vivir allí es como participar en una ruleta rusa donde se gana

24. Ese mutualismo providencial lo encontramos también en Shopenhauer. Para éste autor, "la adaptación a fin [de las estructuras orgánicas] es de dos géneros: en parte es interior, es decir, consiste en una disposición tan armónica de todos los elementos componentes de un organismo único, que resulta de ella la conservación del organismo y la de su especie, presentándose a nosotros como el fin de aquella disposición. Por otra parte, la finalidad es exterior, es decir, consiste en una relación entre la Naturaleza inorgánica y la Naturaleza orgánica en general, o de las partes de la naturaleza entre sí, relación que hace posible la conservación del conjunto del reino orgánico o de especies diferentes de animales, de donde deducimos como consecuencia que aquella relación es el medio para este fin" (Schopenhauer, 1985 [1819], p. 148).

25 En las reflexiones de William Paley, el mutualismo providencial juega ciertamente un papel menos conspicuo que aquel que desempeña en los textos linneanos. Pero, aun así, esa idea se hace presente en aquellas páginas de su Teología natural en la que las hostilidades entre los diferentes seres vivos son previsiblemente consideradas como una forma de controlar una superfecundidad que pondría en peligro el equilibrio natural (cf. Paley, 1809, p. 479-80). 
o se pierde conforme un sistema de reglas que, al igual que aquél de la lotería de Babilonia imaginada por Borges (cf. 1980 [1952]), se trastoca a cada nueva jugada; y, por eso, la virtud que, en cada coyuntura particular, permite sostenerse en el juego ya no puede ser considerada como un dato cómodamente presupuesto sino todo lo contrario: los recursos que hacen posible que cada ser vivo preserve un lugar dentro de ese orden siempre inestable, en el cual se ha transformado la naturaleza, cobran una importancia superlativa y su estudio acaba resultando fundamental para la comprensión de lo viviente. De hecho, el modo por el cual los seres vivos responden al imperativo de sobrevivir en un mundo de escasez se erige en la clave última de los fenómenos biológicos.

Esa preocupación, sin embargo, le era totalmente ajena a naturalistas como Cuvier, Humboldt o Etienne e Isidore Geoffroy Saint-Hilaire. Es que éstos, aún habiendo abandonado el tratamiento explícito del tópico linneano relativo a cómo las diferentes habilidades y particularidades morfológicas de los seres vivos permitían su inserción en la economía natural, aceptaban todavía esa misma idea de economía como un presupuesto a veces implícito pero de hecho nunca cuestionado.

Así, y aunque sin ninguna duda, la insistencia de Cuvier sobre las extinciones contribuyó a erosionar y socavar la idea clásica de economía natural, no es tampoco menos cierto que, desde su perspectiva y como muchos autores lo han subrayado (cf. Saint-Hilaire, 1998 [183o], p. 219; Daudin, 1926b, p. 58; Conry, 1974, p. 363; Limoges, 1976, p. 68; Balan, 1979, p. 159; Kupiec, 2000, p. 19), la presencia de un viviente en el mundo era una necesidad inscripta en un orden por lo general estable y no una frágil e incierta contingencia (cf. Cuvier, 1805, p. 18). De hecho, en su carta a G. M. Ptaff del 17 de noviembre de 1788, Guvier todavía le asignaba a la historia natural el objetivo de "indagar cuidadosamente las relaciones de todos los seres existentes con el resto de la naturaleza y mostrar, sobre todo, su parte en la economía de ese gran todo" (Cuvier apud Daudin, 1926b, p. 58; Limoges, 1976, p. 68); y digo todavía porque es evidente que Cuvier abandonó más tarde ese objetivo, aunque mantuvo la idea de economía natural como presupuesto de sus otras indagaciones.

Pero lo más interesante es que esa idea de economía natural ni siquiera haya sido cuestionada por el transformista Lamarck. Para él, la naturaleza tiende a la manutención de cierto equilibrio u orden en el cual "las razas de los cuerpos vivos subsisten todas pese a sus variaciones" y en el cual "los progresos adquiridos en el perfeccionamiento de la organización nunca se pierden” (Lamarck, 1994 [1809], p. 13o; Barthélemy-Madaule, 1979, p. 128-9; Corsi, 2001, p. 89-90). Para Lamarck, incluso, la extinción sólo podía ocurrir aisladamente y sobre todo por la intervención del hombre (cf. Jacob, 1973, p. 167; Burkhardt, 1995, p. 131; Mayr, 1976, p. 247); y por eso, desde su perspectiva, lo que hoy llamaríamos la viabilidad ecológica del viviente no planteaba ningún interrogante, ni merecía tampoco mayores explicaciones (cf. Limoges, 1976, p. 45-6). 
El tema de la economía natural, podríamos entonces decir, ya no formaba parte de la agenda explícita de la historia natural desarrollada en la primera parte del siglo XIX; pero, aun así, todavía definía y limitaba esa misma agenda tornando innecesaria la pregunta por cómo los diferentes seres vivos conseguían conservar o conquistar su lugar en la naturaleza. Ese lugar se suponía desde el inicio garantizado, siendo por lo tanto algo de esperar el hecho de que cada ser vivo estuviese debidamente dotado para ocuparlo y ejercerlo; y es esa certeza la que explica el escaso interés de Cuvier y de sus contemporáneos por los recursos con los que los seres vivos enfrentaban los diversos retos impuestos por el ambiente en el cual se desarrollaba su existencia.

Es cierto, claro, que el viviente de la historia natural predarwiniana está siempre asediado por la muerte; pero se trata, por decirlo de algún modo, de la muerte fisiológica. Se trata de la misma vieja muerte que asediaba al viviente de Bichat: la interrupción de ese lábil torbellino que es la vida entendida como resistencia a la inercia disgregante de las fuerzas físicas; y es el estudio de las leyes fisiológicas de la organización, y no el de minucias morfológicas que puedan servir como recursos de supervivencia, lo que permite explicar cómo es que el viviente se resiste a esas fuerzas de lo no-vivo que amenazan su integridad. El viviente darwiniano, mientras tanto, esta siempre asediado por otros vivientes que tienden a quitarle su frágil lugar bajo el sol: por eso la sospecha utilitarista de que cada uno de sus perfiles respondía, directa o indirectamente, al imperativo de preservarlo; y por eso también el cambio que se opera, a partir de 1859, en el modo de entender y ejercer el trabajo del naturalista de campo.

\section{EL IMPAGTO DEL DARWINISMO EN EL TRABAJO DE LOS NATURALISTAS DE GAMPO}

En efecto, la significación crucial que la perspectiva darwiniana le otorga a las complejas relaciones que los seres vivos guarden entre sí hace que la observación de las duras condiciones en que éstos desarrollan sus existencias concretas pase a tener una importancia antes desconocida; y esto condujo, inevitablemente, a una alteración substancial del papel a ser jugado por los naturalistas que trabajaban fuera de los limites del museo. Antes de Darwin, el naturalista de campo, el naturalista viajante, era básicamente un colector (cf. Kury, 2001, p. 865): su labor era importante, no en virtud del conocimiento que podían obtener a respecto del modo de vida de los diferentes tipos de organismos en sus condiciones naturales, sino en virtud de los especimenes disecados, o, llegado el caso, de las osamentas fósiles, que podían enviar al museo para, allí, ser catalogados y analizados en cuanto que variaciones dentro de los tipos de organización fisiológica conocidos (cf. Kury, 2001, p. 864) ${ }^{\mathbf{2 6}}$ y por eso debemos resistirnos a la tentación de querer ver en esos naturalistas a ecólogos de campo avant la lettre. 
Muy poco en sus trabajos e informes se aproxima a las tareas que hoy atribuimos a un naturalista en el sentido moderno de la palabra; y para entender cuán grande puede ser la diferencia entre el modo actual y el modo predarwiniano de entender el trabajo del naturalista, se puede recordar aquello que Louis Agassiz decía en abril de 1865 cuando, en una conferencia a bordo del buque Colorado y refiriéndose a las tareas de investigación que su expedición habría de emprender en los ríos del Brasil, pedía a sus colaboradores una particular atención a "las relaciones fundamentales que existen entre los seres" y a "sus relaciones con el medio ambiente". Una atención que, según él mismo decía, iba más allá de lo acostumbrado en la historia natural practicada cincuenta años antes.

En ese entonces, explica Agassiz:

precisar exactamente el lugar del cuál provenía un determinado animal parecía una cosa absolutamente sin importancia para la historia científica de ese animal.[...].Decir que un espécimen provenía de América del Sur era entonces considerado suficiente, y especificar si venía de Brasil o del Plata, del São Francisco o del Amazonas, parecía un lujo para el observador". Así, "en el museo de Paris [...] muchos ejemplares están marcados como venidos de Nueva York o de Pará; pero todo lo que se puede afirmar es que fueron traídos por un navío que partió de esos puertos. Nadie puede decir con exactitud adónde fueron encontrados (Agassiz,1938 [1869], p. 26).

Sin embargo, para los objetivos cognitivos de la historia natural de la era predarwiniana, ese descuido pudo no haber sido algo definitivamente grave. Después de todo, esos especimenes sólo irían a ser examinados en tanto que complejos teoremas de las leyes de la anatomía comparada; y por eso poco importaban cuáles eran las circunstancias y los lugares concretos en los que los mismos vivían o habían sido capturados, recogidos o encontrados.

Los naturalistas viajeros trabajaban básicamente para el engrandecimiento de las colecciones de los museos (cf. Laissus, 1995, p. 51; Lopes, 1995, p. 721). Por eso, más allá de ciertas competencias mínimas para la descripción morfológica, para el dibujo y para la identificación de especies o variedades cuyo análisis fuese de relevancia científica, la excelencia básica de estos naturalistas consistía en saber preparar y acondicionar los especimenes recolectados de modo tal que, pese a las vicisitudes y a las demoras del viaje hasta la metrópoli, los mismos pudiesen llegar a la mesa del anatomista en condi-

26 A este respecto la posición de Cuvier es paradigmática. Ver, en particular, Cuvier, 1861 [1824], p. 279; $197^{8}$ [1800], p. 60 . 
ciones que permitiesen tanto su descripción anátomo-funcional, como su identificación y clasificación (cf. Latour, 1995 , p. 538-9; Drouin, 1997, p. 486-7). Era ahí, después de todo, en el gabinete del anatomista, en donde la verdad más profunda sobre lo viviente habría de rebelarse (cf. Drouin, 2001, p. 847). Esto valía para el espécimen disecado, embalsamado o inmerso en alcohol, y para el fósil, pero también valía para el animal enjaulado que debía llegar vivo a la menagerie o para la planta que viajaba en un vivero portátil rumbo a un jardín botánico o a un invernadero (cf. Laissus, 1995, p. 42-3).

Se nos podría objetar, de todos modos, que la historia natural practicada 50 años de la conferencia que Agassiz profiere en 1865 no es solamente la historia natural de Cuvier o de Etienne Geoffroy Saint-Hilaire; es también la historia natural del "Ensayo sobre la geografía de las plantas" que Humboldt publicó como parte del decimoquinto volumen del Voyage de Humboldt et Bompland en 1805; y los comentarios de Agassiz parecen no hacer justicia del interés humboldtiano en considerar a "los vegetales en función de sus asociaciones locales en los diferentes climas" (Humboldt, 1805, p. 14; 1977 [1845], p. 72). Debemos tener en cuenta, sin embargo, que ese ensayo no es más que el programa de una disciplina de la cual, en aquel momento y como Humboldt (1805, p. 13) mismo apuntaba, sólo existía el nombre; y en ese reconocimiento hay implícito un diagnostico sobre la situación de la historia natural de la época que no parece desmentir lo dicho por Agassiz. Es innegable, de todos modos, que las propuestas y las contribuciones del propio Humboldt propiciaron la reversión de esa situación y contribuyeron para llevar a la historia natural hasta la posición en la que Agassiz podía pronunciar el discurso aquí citado (cf. Bowler, 1998, p. 150). ${ }^{27}$

El espíritu de las recomendaciones que éste les hacía a sus alumnos y colaboradores era, por así decirlo y hasta cierto punto, humboldtiano. Pero digo sólo hasta cierto punto porque, como intenté mostrar más arriba, Humboldt centraba de hecho sus preocupaciones sobre el entorno físico y no sobre el entorno biológico del organismo. Por otro lado, más allá de las correlaciones que su geografía de las plantas intentaba establecer entre tipos de vegetación e isotermas, su vindicación del trabajo del naturalista de campo tenía algo que ver con cierta valoración de la posible captación estética que éste podía tener y trasmitir del paisaje natural como un todo (cf. Radl, 1931, p. 26o; Drouin, 1993, p. 70). Captación ésta que le era negada al historiador natural de gabinete. ${ }^{\mathbf{2} 8}$

27. La influencia de Humboldt fue particularmente importante en la formación de Darwin como naturalista (cf. Desmond \& Moore, 2000, Cap. 8).

28 Este elemento estético de la propuesta de Humboldt no debe ser menospreciado. El mismo está atrás de un cambio en el estilo de exposición del naturalista viajero (cf. Kury, 2001, p. 870). Un cambio de estilo que libera a éste del mero informe descriptivo que era casi obligatorio en el orden cuvieriano; y el Diario del Beagle tal vez sea resultado del ejercicio de esa libertad. Una libertad que Darwin podía, sin duda, permitirse porque no tenía ningún compromiso formal con cualquier historiador natural de la metrópoli. 
Por eso, aún cuando en Humboldt encontremos ya una preocupación por la relación que los organismos guardan con el ambiente que está ausente en la historia natural cuvieriana (cf. Kury, 2001, p. 865) y que, en este caso sí, ya anticipa en algo a una perspectiva ecológica moderna (cf. Limoges, 1976, p. 58; Drouin, 1993, p. 73; Kury, 2001, p. 868), todavía estamos lejos de los puntillosos análisis darwinianos relativos a las complejas relaciones que las diferentes especies biológicas guardan entre sí; y estamos sobre todo muy lejos de esos análisis darwinianos relativos a cómo los diferentes perfiles morfológicos y etológicos de los organismos están marcados por esas relaciones. Comparando el Ensayo sobre la historia natural del cóndor de Humboldt (1811) con las cartas que Darwin y Fritz Müller intercambiaron sobre los más nimios detalles morfológicos de las plantas trepadoras, se puede tener una idea cabal de esa distancia. ${ }^{29}$

Pero claro, Darwin se está carteando con quién él mismo considera el príncipe de los observadores (West, 2003, p. 1): quizá el primer naturalista en el sentido moderno de la palabra; y es significativo que esa correspondencia haya comenzado a circular entre Down y Desterro el mismo año en que Agassiz comenzaba su viaje por Brasil. Algo había cambiado en la historia natural y en el oficio del naturalista desde la no lejana época de oro del Museo Nacional de Historia Natural de Paris; y creo que Müller sabía cuál era la razón de ese cambio. Así, respondiendo a una pregunta que Darwin le formulara en una carta del 20 de septiembre de 1865, Müller escribiría lo siguiente:

\begin{abstract}
Usted preguntó si la historia natural no se tornó extraordinariamente atractiva, a través de las opiniones que ambos sustentamos. Con toda seguridad! Desde que leí su libro sobre el origen de las especies, y desde que me convertí a su opinión, muchos de los hechos que otrora veía con indiferencia, se tornaron excepcionalmente notables. Otros, que antes parecían insignificantes, apenas pura curiosidad, adquirieron un elevado significado y, así, toda la faz de la naturaleza fue alterada (Müller apud Zillig, 1997, p. 125). 30
\end{abstract}

29 Una buena edición de esas cartas puede encontrarse en Zillig, 1997.

3o En esa misma carta (Zillig, 1997, p. 126), Müller también se refiere al viaje de Agassizy al respecto dice lo siguiente: "En este momento el señor L. Agassiz investiga el río Amazonas; como deduzco de una de sus cartas publicadas en un diario de Río, él espera que la distribución geográfica de los peces en aquél río venga a proporcionar pruebas contra la teoría de la transformación. Me parece imposible que un conocimiento relativamente completo de la distribución geográfica de los peces de aquél imponente río, y de sus numerosos afluentes, pueda ser obtenida en un par de años; y no consigo imaginar que se pueda derivar objeción decisiva alguna de un conocimiento incompleto". Yla deducción de Müller era correcta, en la conferencia pronuncciada en el Colorado que aquí hemos citado, Agassiz (p. 25) decía: "El origen de la vida es el gran problema del día. ¿Cómo el mundo orgánico llegó a ser lo que es? He ahí una cuestión sobre la cual debemos desear que nuestro viaje traiga alguna luz. ¿Cómo el Brasil se tornó habitado por los animales y las plantas que en él viven actualmente? [...] ¿Qué razones tenemos para creer que el estado de cosas actual en este país haya derivado de alguna forma de un estado de cosas anterior? 
Y esos hechos son detalles en los perfiles de lo viviente que tienen que ver con dos asuntos ausentes en la historia natural anterior. Uno de ellos es, claro, la propia evolución: los seres vivos actuales son un documento de su historia evolutiva; y esta se pone en evidencia no sólo en la unidad de tipo sino también en un sinnúmero de signos insensatos, la expresión es de Gould (1983, p. 29), como las estructuras vestigiales que aparecen, sea en el organismo adulto, sea en alguna fase de su desarrollo embrionario. Pero el otro de los asuntos antes ausente y que ahora cobra una importancia central es la luch a por la existencia: los perfiles de los vivientes muestran también las vicisitudes pasadas y presentes de las crueles contingencias de esa lucha; y para comprender las marcas que ella deja ya no alcanza con examinar la propia estructura orgánica o comportamental comparándola con las de otras especies.

Para leer esos signos es necesario observar a los seres vivos en toda la variedad de condiciones ambientales en que desarrollan sus existencias concretas y prestando atención a la variada gama de problemas que deben resolver para poder sobrevivir; y eso es algo que se pierde o se desdibuja cuando el viviente es arrancado de su lugar en la naturaleza e integrado en la colección del museo. Las claves últimas de la vida ya no se muestran en la mesa del anatomista; y es necesario buscarlas en la naturaleza. Surgía así el metier del naturalista moderno. Fritz Müller tenía buenas razones para quedarse en Santa Catarina. Los honores podían estar en los museos y universidades de Europa, pero la verdad estaba más a mano, era más visible, en las selvas del valle del Itajaí.@

\author{
Gustavo Gaponi \\ Profesor Doutor do Departamento de Filosofía, \\ Universidade Federal de Santa Catarina. \\ gustavocaponi@newsite.com.br
}

\begin{abstract}
Reiterated references to a presumed predarwinian adaptationism that we found in the present literature about evolutionary biology can produce a distorted image of the subjects and problems which really occupied the predarwinian naturalists and of the importance that these naturalists indeed gave to the study of the complex relations that the morphologic particularities of living beings keep with the environmental exigencies. In this work, I will try to show that this last topic did not occupy an important place in the natural history that immediately precedes the Darwinian Revolution; and I will suggest that this lack of interest was associated with the persistence of an idea of natural economy in which each living being had a function to fulfill and not a place to conquer and to defend. Finally, I will show how the change of attitude towards that topic stimulated by the Darwinism impacted in the work of the field naturalists.
\end{abstract}

KeYwords • Buffon. Cuvier. Darwin. Saint-Hilaire. Humboldt. Lamarck. Paley. 
El VIVIENTE Y SU MEDio: ANTES Y DESPUÉS DE DARWIN

\section{REFERENGIAS BIBLIOGRÁFICAS}

Асот, P. Histoire de l'écologie. Paris: PUF, 1988.

Agassiz, L. Terceira palestra: o que a expedição deve fazer no Brasil. In: Agassiz, L. \& Agassiz, E. (Ed.). Viagem ao Brasil (1865-1866). São Paulo: Companhia Editora Nacional, 1938 [1869]. p. 24-31.

Agassiz, L. \& Agassiz, E. (Ed.). Viagem ao Brasil (1865-1866). São Paulo: Companhia Editora Nacional, 1938 [1869].

Alfonso-Goldfarb, A. \& Maia, G. (Ed.). História da ciência: o mapa do conhecimento. São Paulo, Edusp, 1995 .

Allen, G.; Begkoff, M. \& Lauder, G. (Ed.). Nature's purposes: analysis of function and design in biology. Cambridge: MIT Press, $199^{8}$.

Ameghino, F. Filogenia. Buenos Aires: La Cultura Argentina, 1915 [1884].

Amundson, R. Typology reconsidered: two doctrines on the history of evolutionary biology. Biology and Philosophy, 13, p. 153-77, 1998.

Adaptation and development. In: Orzack, H. \& Sober, E. (Ed.). Adaptationism and optimality.

Cambridge: Cambridge University Press, 2001. p. 3०3-34.

Aristóteles. Histoire des animaux. Trad. de J. Bertier. Paris: Gallimard, 1994.

BaLAN, B. L'ordre et le temps. Paris: Vrin, 1979.

Barrett, P. (Ed.). The collected papers of Charles Darwin. Chicago: University of Chicago Press, 1977.

Barthélemy-Madaule, M. Lamarck ou le myth du précurseur. Paris: Seuil, 1979.

Bentley, G.; Strauss, W. \& Temkin, O. (Ed.). Forerunners of Darwin: 1745-1859. Baltimore: The John Hopkins University Press, 1959.

Biberg, I. L'économie de la nature. In: Linné, C. L'équilibre de la nature. Trad. de B. Jazmín. Introdução e notas de C. Limoges. Paris: Vrin, 1972 [1749]. p. 57-101.

Biezunski, M. (Ed.). La recherche en histoire des sciences. Paris, Seuil, 1983.

Bilbao, G. La ciencia del hombre en el siglo XVIII. Buenos Aires: CEAL, 1978 [1800].

Bock, W. \& Wahlert, G. Adaptation and the form-function complex. In: Allen, C.; Begkoff, M. \& Lauder,

G. (Ed.). Naturés purposes: analysis of function and design in biology. Cambridge: MIT Press, 1998. p. $117-68$.

Borges, J. Otras inquisiciones. In: ___. Prosa completa II. Barcelona: Bruguera, 1980[1952].

Bowler, P. Historia fontana de las ciencias ambientales. México: Fondo de Cultura Económica, 1998.

Buffon, G. Histoire naturelle de l'homme. In: Histoire naturelle genérale et particulière III. Paris:

L'Imprimiere Royale, 1749. p. $37^{1-} 5^{31}$.

. Histoire naturelle genérale et particulière IX. Paris: L'Imprimiere Royale, ${ }_{17} 61$.

De la dégénération des animaux. In: Histoire naturelle genérale et particulière XIV. Paris:

L'Imprimiere Royale, 1766. p. 311-74.

L'âne (de histoire naturelle genérale et particulière iv). In: Pizzetta, J. (Org.). Oeuvres de Buffon. Paris: Parent-Desbarres, 1868 [1753].v. 3. p. 35-4,3.

BuRKHARDt, R. The spirit of system: Lamarck and evolutionary biology. Cambridge: Harvard University Press, 1995 .

CAIn, A. The perfection of animals. Biological Journal of the Linnean Society, 36, 3, p. 3-29, 1989 [1964]. Ganguilhem, G. La connaissance de la vie. Paris: Vrin, 1965.

Caponi, G. La sabiduría de las especies. Ludus Vitalis, 10, 18, p. 3-25, 2002.

Os modos da teleologia em Cuvier, Darwin e Claude Bernard. Scientiae Studia , 1, 1, p. 27-41, 2003. Georges Cuvier: ¿un nombre olvidado en la historia de la fisiología? Asclépio, 56, 1, p. 169-207, 2004a. La navaja de Darwin. Ludus Vitales, 12, 22, p. 9-38, 2004b.

Los objetivos cognitivos de la paleontología cuvieriana. Principia, 8, 2, p. 233-58, 2004c. 
Caponi, G. O darwinismo e seu outro: a teoria transformacional da evolução. Scientiae Studia , 3, 2, p. 233 42,2005 .

Retorno a Limoges: la adaptación en Lamarck. No prelo.

Centre de Regherehe sur L'Histoire des Idées de L’Université de Picardie (Ed.). Lamarck et son temps, Lamarck et notre temps. Paris: Vrin, 1981.

Conry, Y. L'introduction du darwinisme en France au XIXe siècle. Paris: Vrin, 1974.

Consi, P. Lamarck. Paris: CNRS, 2001.

Cronin, H. The ant and the peacock. Cambridge: Cambridge University Press, 1991.

Cuvier, G. Tableau élémentaire de l'histoire naturelle des animaux. Paris: Baudouin, 1798. . Leçons d'anatomie comparée. Paris: Baudouin, 1805 . Le règne animal. Paris: Deterville, 181 z̧a. Mémoires pour servir a l'histoire et a l'anatomie des mollusques. Paris: Deterville, $1817 \mathrm{~b}$.

. Extrait d'un rapport sur l'état de l'histoire naturelle et ses accroissements depuis le retour de la paix maritime. Recueil des éloges historiques lus dans les séances publiques de l'Institute de France. Paris:

F. Didot, 1861[1824]. t. 3. p. 271-92.

. Instrucciones sobre las investigaciones a realizar en torno de las diferencias anatómicas entre las varias razas humanas. In: BilBAO, G. La ciencia del hombre en el siglo XVIII. Buenos Aires: CEAL, $197^{8}$ [1800].p. 57-61.

. Discours préliminaire a las recherches sur les ossements fósiles de quadrupède. Paris: Flammarion, 1992 [1812].

Dantec, F. le. La biologie. Paris: Larousse, 1915.

Darwin, C. On the origin of species. London: Murray, 1859.

The various contrivances by which orchids are fertilized by insects. 2. ed. London: Murray, 1877 .

. Charles Darwin, his life told in an autobiographical chapter and in a selected series of his published letters.

New York: D. Appleton, 1892.

Mi viaje alrededor del mundo. Trad. de G. Piquer. Valencia: Prometéo, 1902 [1845].

. Remarks upon the habits of the genera Geospiza, Camarhynchus, Cactornis, and Certhidea of

Gould. In: Barretr, P. (Ed.). The collected papers of Charles Darwin, Chicago: University of Chicago Press, 1977 [1837], p. 4.0.

A review of Contributions to an insect fauna of the Amazon valley by Henry Bates. In: BarRett, P.

(Ed.). The collected papers of Charles Darwin. Chicago: University of Chicago Press, 1977 [1863]. p. 87-92. Voyage of the Beagle. London: Penguin, 1989 [1839].

. Carta a F. Müller del 20/9/1865. In: Zillig, C. Dearmr. Darwin: a intimidade da correspondência entre Fritz Müller e Charles Darwin. São Paulo: Sky, 1997, p.122.

On the origin of species. 6. ed. New York: The Modern Library, 1998 [1872].

Daudin, H. De Linné à Lamarck: méthodes de la classification et idée de serie en botanique et en zoologie. Paris: Alcan, 1926a.

. Cuvier et Lamarck: les classes zoologiques et l'idée de série animale. 1790-183o. Paris: Alcan, 1926b. v. 1. . Cuvier et Lamarck: les classes zoologiques et l’idée de série animale. 1790-183o. Paris: Alcan, 1927. v. 2.

Desmond, A. \& Moore, J. Darwin: a vida de um evolucionista atormentado. São Paulo: Geração, 2000.

Drouin, J. L'écologie et son histoire. Paris: Flammarion, 1993.

. De Linné à Darwin: les voyageurs naturalists. In: Serres, M. (Ed.). Éléments d'histoire des sciences.

Paris: Larousse, 1997. p. 479-501.

Analogies et contrastes entre l'expédition d'Egypte et le voyage d'Humboldt et Bompland. História,

Ciências, Saúde, 8 , p. 839-62, 2001. Suplemento.

Fabian, A. (Ed.). Evolução: sociedade, ciência e universo. Bauru: Edusc, 2003.

Figueira, R.(Org.). Geografía, ciencia humana. Buenos Aires: CEAL, 1977 [1845]. 
Flourens, P. Histoire des travaux et des idées de Buffon. Paris: Hachette, 1850.

GAYon, J. Darwin et l'après-Darwin. Paris: Kimé, 1992.

Gedner, C. A quoi cela sert-il? In: Linné, G. L'équilibre de la nature. Trad. de B. Jazmín. Introd. e notas de C. Limoges. Paris: Vrin, 1972 [1752]. p. 146-67.

Gillispie, C. Lamarck and Darwin in the history of science. In: Bentley, G.; Strauss, W. \& Temkin, O. (Ed.). Forerunners of Darwin: 1745-1859. Baltimore: The John Hopkins University Press, 1959. p. 265-91.

Gould, S. Los signos insensatos de la historia. In: __. El pulgar del panda. Madrid: Blume, 1983. p. $27-34$.

. Ocho cerditos. Barcelona: Crítica, 1994.

The structure os evolutionary theory. Cambridge: Cambridge University Press, 2002.

Da transmutação da lei de Boyle à revolução de Darwin. In: FABian, A. (Ed.). Evolução: sociedade, ciência e universo. Bauru: Edusc, 2003. p. 11-40.

Guillo, D. Les figures de l'organisation. Paris: PUF, 2003.

Guyader, H. le. Geoffroy Saint-Hilaire. Paris: Belin, 1998 [183o].

Helferich, G. $O$ cosmos de Humboldt. Rio de Janeiro: Objetiva, 2005.

Horta, M. Temas darwinianos. São Paulo, 2005. Tese (Doutorado em Filosofia). Faculdade de Filosofia, Letras e Ciências Humanas, Universidade de São Paulo.

Нum водdт, A. Essai sur le géographie des plantes. In: Нum водdт, A. \& Bompland, A. Voyage de Humboldt et Bompland XV. Paris: Lebrault \& Schoell, 1805 . p. $13-35$.

. Essai sur l'histoire naturalle du condor. In: Humboldt, A. \& Bompland, A. Voyage de Humboldt et Bompland, deuxième partie, observations de zoologie et d'anatomie compare. Paris: Schoell \& Dufour, 1811. p. 26-45.

. Introducción a cosmos. Ensayo de una descripción física del mundo. In: Figueira, R. (Org.). Geografía, ciencia humana. Buenos Aires: CEAL, 1977 [1845]. p. 39-84.

. Viaje a las regiones equinocciales del nuevo mundo II. Caracas: Monte Ávila, 1991a [1802].

. Viaje a las regiones equinocciales del nuevo mundo III. Caracas: Monte Ávila, 1991b [1802].

Viaje a las regiones equinocciales del nuevo mundo IV. Caracas: Monte Ávila, 1991c [1802].

Humboldt, A. \& Bompland, A. Voyage de Humboldt et Bompland xV. Paris: Lebrault \& Schoell, 1805.

Voyage de Humboldt et Bompland, deuxième partie, observations de zoologie et d'anatomie compare.

Paris: Schoell \& Dufour, 1811.

Јасов, F. La lógica de lo viviente. Barcelona: Laia, 1973.

James, W. Pragmatism. New York: Meridian, 1974 [1907].

Jordanova, L. Lamarck. México: Fondo de Cultura Económica, 1990.

Kupiec, J. Histoire d'être. In: Kupiec, J. \& Sonigo, P. (Ed.). Ni Dieu ni gène. Paris: Seuil, 2000. p.15-84.

Kupiec, J. \& Sonigo, P. (Ed.). Ni Dieu ni gène. Paris: Seuil, 2000.

KuRY, L. Viajantes-naturalistas no Brasil oitocentista: experiência, relato e imagem. História, Ciências,

Saúde, 8 , p.863-80, 2001. Suplemento.

LaIssus, Y. Le Muséum National d'Histoire Naturelle. Paris: Gallimard, 1995.

Lamarck, J. Philosophie zoologique. Paris: Flammarion, 1994 [1809].

Latour, B. La science en action. Paris: Gallimard, 1995.

Limoges, C. Introduction a Linné. In: Linné, C. L'équilibre de la nature. Trad. de B. Jazmín. Introd. e notas de C. Limoges. Paris: Vrin, 1972. p. 7-22.

La selección natural. México: Siglo xxi, 1976.

Linné, C. L'équilibre de la nature. Trad. de B. Jazmín. Introd. e notas de C. Limoges. Paris: Vrin, 1972.

Liтtré, É. Cuvier et les ossements fósiles. In: . (Ed.). La science au point de vue philosophique. Paris:

Fayard, 1997 [1834].p. 147-66. 
Lopes, M. As ciências dos museus: a história natural, os viajantes europeus e as diferentes concepções de museus no Brasil do século xix. In: Alfonso-Goldfarb, A. \& Maia, C. (Ed.). História da ciência: o mapa do conhecimento. São Paulo, Edusp, 1995 - p. 721-32.

MAYR, E. Lamarck revisited. In: Evolution and the diversity of life. Cambridge: Harvard University Press, 1976. p. 222-50.

Una larga controversia: Darwin y el darwinismo. Barcelona: Crítica, 1992.

MaZLIAK, P. Les fondements de la biologie: le XIX siècle de Darwin, Pasteur e Claude Bernard. Paris: VuibertAdapt, 2002.

Milne-Edwards, H. Rapport sur les progrès récents des sciences zoologiques en France. Paris: Hachette, 1867.

Müller, F. Carta a Darwin del 5/111865. In: Zillig, G. Dear Mr. Darwin: a intimidade da correspondência entre Fritz Müller e Charles Darwin. São Paulo: Sky, 1997, p. 125-6.

NordenskiöLd, E. Evolución histórica de las ciencias biológicas. Buenos Aires: Espasa Calpe, 1949.

Orzack, H. \& Sober, E. (Ed).Adaptationism and optimality. Cambridge: Cambridge University Press, 2001.

Osborne, M. Nature, the exotic, and the science of French colonialism. Indianapolis: Indiana University Press, 1994 .

Paley, W. Natural theology. 12. ed. London: John Faulder, 1809.

Papavero, N.; Teixeira, D. \& Llorente-Bousquets, J. História da biogeografía no período pré-evolutivo. São Paulo: Plêiade, 1997 .

Piснот, A. Histoire de la notion de vie. Paris: Gallimard, 1993. Histoire de la notion de gene. Paris: Flammarion, 1999.

Pinto, E. R. Gloria sem rumor. In: Fritz Müller: reflexões biográficas. Blumenau: Cultura em Movimento, 2000 [1929]. p. 13-4.9.

Pizzetta, J. (Org.). Oeuvres de Buffon. Paris: Parent-Desbarres, 1868. $10 \mathrm{v}$.

RADL, E. Historia de las teorías biológicas ii. Madrid: Biblioteca de la Revista de Occidente, 1931.

Rенвоск, P. The philosophical naturalists: themes in early nineteenth century. Madison: University of Wisconsin Press, 1983.

Roger, J. Buffon et le transformisme. In: BiezUnski, M. (Ed.). La recherche en histoire des sciences. Paris, Seuil, 1983. p. 149-72.

Rostand, J. Les grands problèmes de la biologie. In: Taton, R. (Ed.). La science moderne: de 1450 a 1800. Paris: PUF, 1958. p. 597-618.

Ruse, M. La revolución darwinista. Madrid: Alianza, 1983.

Evolución y progreso: crónica de dos conceptos. In: Wagensberg, J. \& Agustí, J. (Ed.). El progreso: ¿un concepto acabado o emergente? Barcelona: Tusquets, 1998. p. 67-106.

. The darwinian revolution, as seem in 1979 and as seen 25 years later in 2004. Journal of the History of Biology, 38, p. 33-45, 2005.

RusselL, E. S. Form and function. London: Murray, 1916.

Saint-Hilaire, E. G. Principes de philosophie zoologique. In: Le Guyader, H. Geoffroy Saint-Hilaire. Paris: Belin, 1998 [183o].p. 130-237.

Saint-Hilaire, I. G. Histoire naturelle générale des régnes organiques. Paris: Masson, 1859, t. 2. . Acclimatation et domestication des animaux utiles. Paris: Librairie Agricole de la Maison Rustique, 1861.

Schopenhauer, A. Sobre la voluntad en la naturaleza. Buenos Aires: Siglo xx, 1947 [1857]. El mundo como voluntad y representación. Madrid: Orbis, 1985 [1819].

Serres, M. (Ed.). Éléments d'histoire des sciences. Paris: Larousse, 1997.

Shanahan, T. The evolution of darwinism. Cambridge: Cambridge University Press, 2004.

Solanet, E. Pelajes criollos. Buenos Aires: Fondo Editorial Agropecuario, 1971.

Taton, R. (Ed.). La science moderne: de 1450 a 1800. Paris: PUF, $195^{8}$. 
El VIVIENTE Y SU MEDio: ANTES Y DESPUÉS DE DARWIN

Tetry, A. Hérédité ou non-hérédité des caractères acquis par le soma: problème explosif. In: Gentre DE Regherche sur L'Histoire des Idées de L'Université de Picardie (Ed.). Lamarck et son temps, Lamarck et notre temps. Paris: Vrin, 1981. p. 143-58.

Wagensberg, J. \& Agustí, J. (Ed.). El progreso: ¿un concepto acabado o emergente? Barcelona: Tusquets, 1998.

WALLAGE, A. R. Natural selection and tropical nature - essays on descriptive and theoretical biology. London: Macmillan, 1891.

Weiner, J. O bico do tentilhão. Rio de Janeiro: Rocco, 1995.

West, D. Fritz Müller, a naturalist in Brazil. Blackburns: Pocahontas Press, 2003.

WiLke, H. La police de la nature. In: Linné, C. L'équilibre de la nature. Trad. de B. Jazmín. Introd. e notas de C. Limoges. Paris: Vrin, 1972 [1960]. p. 103-21.

Zillig, C. Dear mr. Darwin: a intimidade da correspondência entre Fritz Müller e Charles Darwin. São Paulo: Sky, 1997 . 